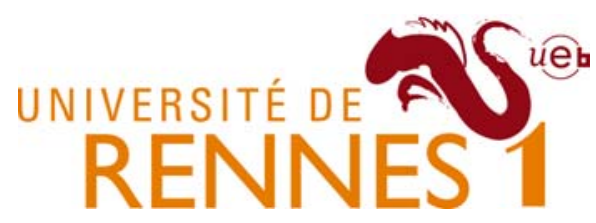

This is the author's final draft post-refeering (post-print)

Find more peer-reviewed articles on our open access repository:

http://hal-univ-rennes1.archives-ouvertes.fr/ 


\title{
Defluoridation of water via Light Weight Expanded Clay Aggregate (LECA): Adsorbent characterization, competing ions, chemical regeneration, equilibrium and kinetic modeling
}

\author{
Mohammad Noori Sepehr ${ }^{\mathrm{a}}$, Hossein Kazemian ${ }^{\mathrm{b}}$, Esmail Ghahramani ${ }^{\mathrm{c}}$, Abdeltif Amrane ${ }^{\mathrm{d}}$, \\ V. Sivasankar ${ }^{\mathrm{e}}$, Mansur Zarrabi ${ }^{\mathrm{a}, *}$ \\ a Department of Environmental Health Engineering, Faculty of Health, Alborz University of Medical Sciences, Karaj, Iran \\ ${ }^{\mathrm{b}}$ Department of Chemical and Biochemical Engineering, Western University, London, ON N6A5B9, Canada \\ ${ }^{\mathrm{c}}$ Kurdistan Environmental Health Research Center, Kurdistan University of Medical Sciences, Sanandaj, Iran \\ ${ }^{\mathrm{d}}$ Ecole Nationale Supérieure de Chimie de Rennes, Université de Rennes 1, CNRS, UMR 6226, Avenue du Général Leclerc, CS 50837, Rennes Cedex 7 35708, \\ France \\ ${ }^{\mathrm{e}}$ Department of Chemistry, Thiagarajar College of Engineering (Autonomous), Madurai - 625 015, India
}

\begin{abstract}
A B S T R A C T
Natural, $\mathrm{H}_{2} \mathrm{O}_{2}$ and $\mathrm{MgCl}_{2}$ - modified Light Weight Expanded Clay Aggregate (LECA) were used as fluoride adsorbents. Characterization of LECA and its modified forms was done by infra-red, X-ray diffraction, scanning electron microscope and X-ray fluorescence studies. The specific surface area of HML and MGML was 3.34 and 3.97 times greater than that of $\mathrm{NL}\left(11.72 \mathrm{~m}^{2} / \mathrm{g}\right)$. Improved chemical composition of Magnesium (as oxide) to $15.6 \%$ by $2 \mathrm{M} \mathrm{MgCl}_{2}$ solution was ascertained through XRF results. The fluoride levels were reduced (within the safe limit of WHO: $0.5-1.5 \mathrm{mg} / \mathrm{L}^{-1}$ ) to $0.39 \mathrm{mg} / \mathrm{L}, 1.0 \mathrm{mg} / \mathrm{L}$ and $0.075 \mathrm{mg} /$ $\mathrm{L}$ respectively using natural (NL), $\mathrm{H}_{2} \mathrm{O}_{2}(\mathrm{HML})$ and $\mathrm{MgCl}_{2}$ - modified LECA (MGML) at a pH of 6.0 and initial fluoride concentration of $10 \mathrm{~g} / \mathrm{L}$ for an equilibrium time of $120 \mathrm{~min}$. The sorption capacities of $8.53 \mathrm{mg} / \mathrm{g}, 17.83 \mathrm{mg} / \mathrm{g}$ and $23.86 \mathrm{mg} / \mathrm{g}$ were determined for NL, HML and MGML respectively. Validation of kinetic and isotherm models was checked for the present fluoride sorption dynamics. The thermodynamic data revealed that the present fluoride sorption was spontaneous, exothermic and ends up with decrease in randomness. Prediction of fluoride sorption mechanism for onto natural and modified LECA forms was also elucidated. Chloride and sulfate were the highly competing species against fluoride sorption. Regeneration efficiency of the spent LECA materials prompted the ability of MGML even after five cycles of adsorption-regeneration processes.
\end{abstract}

\section{Introduction}

Fluoride ions naturally exist in soils and rock in various concentrations and are then introduced to surface water from snowmelt, rivers and streams, as well as groundwater [1]. Fluoride concentration in surface water is usually less than $1 \mathrm{mg} / \mathrm{L}$, while lower or higher concentration of fluoride in groundwater is observed, depending on the nature of soils or rocks [2]. Fluoride is an essential element for human health body, since in standard levels $(0.75-1.5 \mathrm{mg} / \mathrm{L})$ it prevents tooth decay [3]. If fluoride concentration in drinking water exceeds standard levels, it can lead to various diseases such as osteoporosis, arthritis, brittle bones,

\footnotetext{
* Corresponding author. Tel.: +98 2614336007/9; fax: +98 2614319188. E-mail address: mansor62@gmail.com (M. Zarrabi).
}

cancer, infertility, brain damage, Alzheimer syndrome, and thyroid disorder [4]. Fluorosis is a common disorder of ingestion of high levels of fluoride in which teeth and bones are damaged. Skeletal fluorosis is another health aspect of excessive fluoride which is characterized by increased bone brittleness and a greater risk of fractures [5,6]. In addition, fluoride can interfere in DNA synthesis, as well as in metabolism of lipids, carbohydrates, proteins and other minerals [6]. Despite the natural origin of fluoride in the environment, many industrial activities such as pharmacy, fluorspar mining, semiconductor process, aluminum electrolysis, and electroplating, generating electricity, rubber and fertilizer production release fluoride into environment and water bodies [7]. In Iran, fluoride concentrations ranging from zero to as high level as $20 \mathrm{mg} / \mathrm{L}$ can be found in groundwater resource. Since appropriate levels of fluoride are necessary to bones and skeletal health, while too high levels can damage human being, many works have been 
done on fluoridation-defluoridation of drinking water. In practice, two distinct methods are used for the removal of fluoride from aquatic solutions: sorption process and precipitation. Calcium and aluminum salts are used for the precipitation of fluoride ions in industrial wastewater. The latter produce significant amounts of sludge which have to be treated to obtain a final safe product [6]. In recent years, many researchers tested adsorption processes for fluoride removal, involving among others Mn-Ce oxide [1], ceramic adsorbent [2], natural stilbite zeolite modified with Fe (III) [3], acid activated water treatment sludge [5], bi-metal doped micro- and nano multi-functional polymeric adsorbents [8]. Lightweight expanded clay aggregate (LECA) is characterized by a low density, a high porosity, its natural $\mathrm{pH}$ and its thermal resistance (up to $1000^{\circ} \mathrm{C}$ ). LECA has tiny pores that retain moisture which act as air pockets to facilitate floating on water. The appearance of LECA is dark brown, leading to its use as building material for centuries [9]. Because of its porous structure, it can adsorb and retain environmental pollutants. The main aim of the present work was therefore to evaluate LECA for adsorption of fluoride ions from contaminated water. Indeed, although LECA has been widely used to remove several environmental pollutants, to the best of our knowledge its use for fluoride removal has not been reported yet. In addition, the studied LECA was modified with $\mathrm{MgCl}_{2}$ and $\mathrm{H}_{2} \mathrm{O}_{2}$ in order to improve its adsorption capacity.

\section{Materials and methods}

\subsection{Chemicals}

All chemicals used in this work were obtained from Merck Co. Analytical grade NaF was used for the preparation of fluoride stock solution by dissolving an appropriate amount in deionized water. The solution $\mathrm{pH}$ was adjusted and controlled during experiments using $0.5 \mathrm{~N} \mathrm{NaOH}$ or $\mathrm{H}_{2} \mathrm{SO}_{4}$ and measured by means of a Jenway, model 3510 pH-meter. $2 \mathrm{M} \mathrm{MgCl}_{2}$ or $30 \% \mathrm{H}_{2} \mathrm{O}_{2}$ were used for adsorbent treatment. The natural LECA was purchased from Teb Azma Co. (Karaj, Iran).

\subsection{Adsorbent preparation}

Natural LECA (NL), $\mathrm{H}_{2} \mathrm{O}_{2}$-modified LECA (HML) and $\mathrm{MgCl}_{2}$ modified LECA (MGML) were tested for fluoride removal from synthetic solutions. The adsorbent was first washed several times with deionized water to remove any soil impurity until the turbidity reached a value below 1 NTU. After primary washing, the adsorbent was dried at $110^{\circ} \mathrm{C}$ for $24 \mathrm{~h}$ to evaporate the remaining water molecules. The dried adsorbent was then pulverized and sieved to 10-30 meshes (841-2000 $\mu \mathrm{m})$.

Regarding $\mathrm{MgCl}_{2}$-modified LECA (MGML), it was prepared by transferring a portion of powdered LECA to a $1 \mathrm{~L}$ beaker contained $2 \mathrm{M} \mathrm{MgCl}_{2}$ solution and mixed for $24 \mathrm{~h}$. The liquid to solid ratio was 50 . Then, the modified adsorbent was filtered using a $0.45 \mu \mathrm{m}$ filter (Whatman) and rinsed with deionized water to remove $\mathrm{MgCl}_{2}$ in excess; it was then dried at $110^{\circ} \mathrm{C}$ for $24 \mathrm{~h}$ for subsequent use.

The same method was used to prepare the $\mathrm{H}_{2} \mathrm{O}_{2}$-modified adsorbent.

\subsection{Batch experiments}

All experiments were conducted in batch mode in $250 \mathrm{~mL}$ polyethylene flasks. The following experimental parameters were investigated: $\mathrm{pH}(2-10)$, temperature $\left(10-50{ }^{\circ} \mathrm{C}\right)$, adsorbent mass (2$10 \mathrm{~g} / \mathrm{L})$, initial fluoride concentration (5-20 mg/L) and contact time. Optimized adsorption time for natural and modified LECA adsorbents were examined by varying the contact time at room temperature, $\mathrm{pH} 7$ and using $6 \mathrm{~g} / \mathrm{L}$ of adsorbent. For this purpose,
$6 \mathrm{~g}$ of adsorbent was added to $1 \mathrm{~L}$ of solution in a polyethylene flask containing fluoride ions at concentrations in the range 5 to $15 \mathrm{mg} / \mathrm{L}$. The mixture was shaken at $200 \mathrm{rpm}$ (Hanna-Hi 190 M, Singapore). Samples were taken at predetermined time intervals, filtered (0.45 $\mu \mathrm{m}$, Whatman), centrifuged (Sigma-301, Germany) and the fluoride concentration was measured at a maximum wavelength of $570 \mathrm{~nm}$ by means of an UV-vis spectrophotometer (model 1700, Shimadzu, Japan) according to standard methods for the examination of water and wastewater [10]. The removal efficiency (RE) was calculated by means of the following equation (Eq. 1):

$\mathrm{RE}=\left(C_{0}-C_{\mathrm{e}}\right) \times \frac{100}{C_{0}}$

where $R E(\%)$ is the percentage of fluoride removed at equilibrium time; $C_{0}$ and $C_{\mathrm{e}}$ are the initial and equilibrium concentrations of chromium $(\mathrm{mg} / \mathrm{L})$, respectively.

\subsection{Adsorbent effect on electrical conductivity (EC) and turbidity}

In order to measure the influence of adsorbents on EC and turbidity of water, $6 \mathrm{~g} / \mathrm{L}$ of (natural or modified) adsorbent was taken in $250 \mathrm{~mL}$ of deionized water (i.e., free of fluoride ions) at $\mathrm{pH}$ 7 and shaken for $200 \mathrm{~min}$ at $200 \mathrm{rpm}$. At regular time intervals, samples were taken for conductivity and turbidity measurements (Jenway, Model 4520).

\subsection{Isotherm study}

Equilibrium experiments were conducted in $250 \mathrm{~mL}$ polyethylene flasks by adding $6 \mathrm{~g} / \mathrm{L}$ of NL, HML and MGML to $250 \mathrm{~mL}$ of fluoride solution at concentrations ranging from 5 to $20 \mathrm{mg} / \mathrm{L}$. The mixture was shaken at $200 \mathrm{rpm}$ for $6 \mathrm{~h}$ at $25^{\circ} \mathrm{C}$ to ensure that maximum sorption was achieved. Adsorption results were then analyzed by Langmuir, Freundlich and Temkin isotherm models. The Langmuir isotherm model is based on the assumption of a homogenous surface energy distribution. The non-linear Eq. (2) and linear Eq. (3) shapes of the Langmuir model are described as follows:

$q_{\mathrm{e}}=\frac{\left(q_{\mathrm{m}} b C_{\mathrm{e}}\right)}{\left(1+b C_{\mathrm{e}}\right)}$

$\frac{C_{\mathrm{e}}}{q_{\mathrm{e}}}=\frac{C_{\mathrm{e}}}{q_{\mathrm{m}}}+\frac{1}{\left(q_{\mathrm{m}} b\right)}$

where $q_{\mathrm{e}}$ is the equilibrium amount of adsorbate $(\mathrm{mg} / \mathrm{g}), C_{\mathrm{e}}$ is the equilibrium concentration of adsorbate $(\mathrm{mg} / \mathrm{L}), q_{\mathrm{m}}$ is the maximum adsorption capacity $(\mathrm{mg} / \mathrm{g})$ and $b(\mathrm{~L} / \mathrm{mg})$ is the Langmuir constant. The important feature of the Langmuir model can be described based on the $R_{\mathrm{L}}$ parameter expressed in Eq. (4):

$R_{\mathrm{L}}=\frac{1}{\left(1+b C_{0}\right)}$

Adsorption is unfavorable for $R_{\mathrm{L}}>1$, linear for $R_{\mathrm{L}}=1$, favorable for $0<R_{\mathrm{L}}<1$ and irreversible for $R_{\mathrm{L}}=0$.

The Freundlich isotherm model which is appropriate for heterogeneous systems is expressed in Eqs. (5) and (6).

$q_{\mathrm{e}}=K_{\mathrm{f}} C_{\mathrm{e}}^{1 / n}$

$\log \left(q_{\mathrm{e}}\right)=\log K_{\mathrm{f}}+\frac{1}{n \log C_{\mathrm{e}}}$

where, $q_{\mathrm{e}}$ is the amount of adsorbate $(\mathrm{mg} / \mathrm{g}), C_{\mathrm{e}}$ is the equilibrium concentration of adsorbate $(\mathrm{mg} / \mathrm{L}), K_{\mathrm{f}}\left(\mathrm{mg}^{1-1 / n} / \mathrm{L}^{1 / n} / \mathrm{g}\right)$ and $1 / n$ are the Freundlich constants. The affinity of the adsorbate is linked to large values. For a favorable adsorption, the value of the Freundlich constant $(n)$ should be in the range of 1-10. 
The Temkin isotherm is also available for heterogeneous surface adsorption. The non-linear and linear forms of the Temkin model are given by Eqs. (7) and (8):

$q_{\mathrm{e}}=\frac{\mathrm{RT}}{b_{1}} \ln \left(k_{\mathrm{t}} C_{\mathrm{e}}\right)$

$q_{\mathrm{e}}=B_{1} \ln \left(k_{\mathrm{t}}\right)+B_{1} \ln \left(C_{\mathrm{e}}\right)$

where $B_{1}=\mathrm{RT} / b_{1}, b_{1}$ is the adsorption heat $(\mathrm{kJ} / \mathrm{mol})$ and $k_{\mathrm{t}}$ is the equilibrium binding constant $(\mathrm{L} / \mathrm{g})$ corresponding to the maximum binding energy. A high value of $b_{1}$ shows a fast sorption of adsorbate at initial stage. Similarly, a low $k_{\mathrm{t}}$ value is related to weak bonding of adsorbate onto the medium. By plotting $q_{\mathrm{e}}$ versus $\ln \left(C_{\mathrm{e}}\right)$ one can deduce $b_{1}$ and $k_{\mathrm{t}}$ from the slope and the intercept of this curve, respectively.

\subsection{Kinetic modeling}

Equilibrium time data were used to investigate kinetic model. For this purpose, $6 \mathrm{~g} / \mathrm{L}$ of natural and modified adsorbent were added onto $250 \mathrm{~mL}$ fluoride solution containing $5-20 \mathrm{mg} / \mathrm{L}$ solute. The $\mathrm{pH}$ was adjusted at 6 and then shaken at $200 \mathrm{rpm}$. Samples were taken at regular time intervals to determine the solute concentration. Pseudo-first order, pseudo-second order and modified pseudo-first order kinetic models were considered.

\subsubsection{Pseudo-first order model}

Pseudo-first order kinetics is described by the following equation Eq. (9) [11]:

$\frac{\mathrm{d} q_{\mathrm{t}}}{\mathrm{d} t}=k_{1}\left(q_{\mathrm{e}}-q_{\mathrm{t}}\right)$

where $q_{\mathrm{e}}$ and $q_{\mathrm{t}}$ are the amounts ( $\mathrm{mg} / \mathrm{g}$ ) of adsorbate at equilibrium and at time $t$ ( $\mathrm{min}$ ) respectively; and $k_{1}$ is the rate constant $(1 / \mathrm{min})$. Integration of Eq. (9) at the boundary, $q_{\mathrm{t}}=0$ at $t=0$ and $q_{\mathrm{t}}=q_{\mathrm{t}}$ at $t=t$, gives Eq. (10):

$\log \left(1-\frac{q_{t}}{q_{\mathrm{e}}}\right)=-\left(\frac{k_{1}}{2.303}\right) t$

\subsubsection{Pseudo-second order model}

Pseudo-second order kinetics is expressed as follows Eq. (11) [11]:

$\frac{\mathrm{d} q_{\mathrm{t}}}{\mathrm{d} t}=k_{2}\left(q_{\mathrm{e}}-q_{\mathrm{t}}\right)^{2}$

where $k_{2}$ is the rate constant ( $\mathrm{g} / \mathrm{mg}$ min). Integration of Eq. (11) at the boundary, $q_{\mathrm{t}}=0$ at $t=0$ and $q_{\mathrm{t}}=q_{\mathrm{t}}$ at $t=t$ and then rearrangement to a linear form gives Eq. (12):

$\frac{t}{q_{\mathrm{t}}}=\frac{1}{k_{2} q_{\mathrm{e}}^{2}}+\frac{1}{q_{\mathrm{e}}^{t}}$

The value of $k_{2}$ and $q_{\mathrm{e}}$ can be determined from the slope and the intercept of the plot $t / q_{\mathrm{t}}$ versus $t$, respectively.

\subsubsection{Modified pseudo-first order model}

The modified pseudo-first order model which was first empirically proposed by Yang and Al-Dury [12] and then theoretically derived by Azizian and Bashiri [13] and is given by Eq. (13):

$\frac{\mathrm{d} q_{\mathrm{t}}}{\mathrm{d} t}=k_{m}\left(\frac{q_{\mathrm{e}}}{q_{\mathrm{t}}}\right)\left(q_{\mathrm{e}}-q_{\mathrm{t}}\right)$

Integration of Eq. (13) at the boundary conditions mentioned above leads to the following equation Eq. (14):

$\ln \left(1-\frac{q_{\mathrm{t}}}{q_{\mathrm{e}}}\right)+\frac{q_{\mathrm{t}}}{q_{\mathrm{e}}}=-k_{\mathrm{m}} t$

\subsection{Regeneration of the spent adsorbents}

Regeneration tests for spent NL, HML and MGML were carried out using deionized water, $\mathrm{H}_{2} \mathrm{O}_{2}(30 \% \mathrm{v} / \mathrm{v})$ and $2 \mathrm{M} \mathrm{MgCl}_{2}$ solutions, respectively. To saturate the adsorbents, experiments were conducted with $6 \mathrm{~g} / \mathrm{L}$ of adsorbent in $250 \mathrm{~mL}$ solution containing $10 \mathrm{mg} / \mathrm{L}$ fluoride and stirred at $200 \mathrm{rpm}$ until equilibrium was reached. The spent adsorbent was filtered, washed and dried at $55^{\circ} \mathrm{C}$ for $24 \mathrm{~h}$. The dried spent adsorbent was then added to deionized water, $\mathrm{H}_{2} \mathrm{O}_{2}(30 \% \mathrm{v} / \mathrm{v})$ or $2 \mathrm{M} \mathrm{MgCl}_{2}$ solution and let for $500 \mathrm{~min}$; it was then filtered, washed several times with deionized water and dried at $55{ }^{\circ} \mathrm{C}$ for $24 \mathrm{~h}$. The regenerated adsorbent was then tested for the adsorption of fluoride. The regeneration percentage was calculated based on the comparison of the removal efficiencies of fresh and regenerated adsorbents.

\subsection{Determination of the zero point charge}

The zero point charge was determined using $0.01 \mathrm{M}$ solution of $\mathrm{NaCl}$ as electrolyte by adding $0.1 \mathrm{M}$ solutions of $\mathrm{NaOH}$ or $\mathrm{HCl}$. For this purpose, $50 \mathrm{~mL}$ electrolytes were introduced in beakers ( 8 on the whole); $\mathrm{pH}$ was set to the desirable values in the range 2-12.0.5 gram portions of adsorbent was then added into each beaker and shaken for $48 \mathrm{~h}$. The solutions were then filtered to remove the adsorbent and the final $\mathrm{pH}$ of each beaker was measured. By plotting the initial $\mathrm{pH}$ versus the $\mathrm{pH}$ after $48 \mathrm{~h}$ of agitation, the zero point charge of the adsorbents determined to be 5.7,6.1 and 5.9 for natural, $\mathrm{H}_{2} \mathrm{O}_{2}$-modified and $\mathrm{MgCl}_{2}$-modified LECA respectively.

\subsection{Effect of competing ions}

The effects of chloride ( $250 \mathrm{mg} / \mathrm{L})$, nitrate $(35 \mathrm{mg} / \mathrm{L})$, calcium $(50 \mathrm{mg} / \mathrm{L})$, magnesium $(50 \mathrm{mg} / \mathrm{L})$ and sulfate $(350 \mathrm{mg} / \mathrm{L})$ were examined. Conductivity and total dissolved solid (TDS) of water solutions were adjusted by sodium chloride at $1850 \mu \mathrm{s} / \mathrm{cm}$ and $1150 \mathrm{mg} / \mathrm{L}$, respectively. The simulated real sample was prepared according to Karaj water supply system with some modifications.

\section{Results and discussion}

\subsection{Adsorbent characteristics}

The chemical compositions of the natural LECA (NL), $\mathrm{H}_{2} \mathrm{O}_{2}-$ modified (HML) and $\mathrm{MgCl}_{2}$-modified (MGML) adsorbents were determined by means of an X-ray fluorescence spectroscopy (XRF) instrument (Philips-Magix Pro, Netherland) and are summarized in Table 1 . According to the results, the natural LECA was a typical aluminosilicate mineral with $\mathrm{SiO}_{2} / \mathrm{Al}_{2} \mathrm{O}_{3}$ ratio of 3.33. The chemical

Table 1

Chemical compositions of the natural LECA and its $\mathrm{MgCl}_{2}$ - and $\mathrm{H}_{2} \mathrm{O}_{2}$-modified forms and comparison to values reported in the literature [10].

\begin{tabular}{lllll}
\hline \multirow{2}{*}{ Component } & \multicolumn{2}{l}{ wt\% } & & \\
\cline { 2 - 5 } & $\mathrm{NL}$ & $\mathrm{HML}$ & $\mathrm{MGML}$ & Ref. [14] \\
\hline $\mathrm{SiO}_{2}$ & 61.67 & 62.64 & 57.82 & 62 \\
$\mathrm{Al}_{2} \mathrm{O}_{3}$ & 18.51 & 18.08 & 16.47 & 18 \\
$\mathrm{MgO}$ & 3.97 & 3.62 & 4.59 & 3 \\
$\mathrm{P}_{2} \mathrm{O}_{5}$ & 0.19 & 0.22 & 0.18 & - \\
$\mathrm{SO}_{3}$ & 0.23 & 0.24 & 0.21 & - \\
$\mathrm{K}_{2} \mathrm{O}$ & 3.28 & 3.31 & 2.99 & 4 \\
$\mathrm{CaO}$ & 3.50 & 3.52 & 3.22 & 3 \\
$\mathrm{TiO}_{2}$ & 0.65 & 0.69 & 0.60 & - \\
$\mathrm{Fe}_{2} \mathrm{O}_{3}$ & 6.14 & 5.83 & 6.03 & 7 \\
$\mathrm{SrO}$ & 0.13 & 0.13 & 0.13 & - \\
$\mathrm{Na}_{2} \mathrm{O}$ & 1.54 & 1.50 & 1.41 & 2 \\
$\mathrm{Cl}^{-}$ & - & - & 1.65 & - \\
$\mathrm{SiO}_{2} / \mathrm{Al}_{2} \mathrm{O}_{3}$ & 3.33, & 3.46 & 3.51 & 3.44 \\
\hline
\end{tabular}


composition and the Si/Al ratio of the NL were very similar to those reported in the literature [14]. The BET (nitrogen sorption isothermModel ASAP 2000) specific surface area for the natural material was $11.72 \mathrm{~m}^{2} / \mathrm{g}$; while it remarkably increased to 53.72 and $76.12 \mathrm{~m}^{2} / \mathrm{g}$ after modification with $\mathrm{H}_{2} \mathrm{O}_{2}$ and $\mathrm{MgCl}_{2}$, respectively.

The chemical analysis data revealed that $\mathrm{Mg}^{2+}$ modification of the NL led to an exchange of magnesium cations with other mobile cations including calcium, sodium and potassium, leading to an increase of the $\mathrm{MgO}$ content of the MGML by $0.62 \%$ and a decrease of the $\mathrm{CaO}, \mathrm{K}_{2} \mathrm{O}$ and $\mathrm{Na}_{2} \mathrm{O}$ contents by $0.28 \%, 0.29 \%$ and $0.13 \%$, respectively. From this and taking into account the XRD patterns, which showed quite similar patterns for NL and MGML adsorbents, it can be suggested that the dominant mechanism of modification was ion-exchange. On the other hand, the chemical composition of the $\mathrm{H}_{2} \mathrm{O}_{2}$-modified sample remained very close to the $\mathrm{NL}$, suggesting an almost negligible impact of hydrogen peroxide on the chemical composition of the modified LECA.

The XRD patterns of the NL and its modified counterparts (i.e., HML and MGML), which were collected by means of a PHILIPS Xpert pro with $\mathrm{Cu} \mathrm{K} \alpha$ radiations $\left(1.54056 \mathrm{~A}^{\circ}\right)$ generated at $40 \mathrm{kV}$ and $40 \mathrm{~mA}$ are displayed in Fig. 1a-c. The XRD analysis confirmed the mineralogical composition of the samples. The $\mathrm{X}$ high background and a very broad peak clearly indicated the presence of amorphous phase in the samples. Apart from amorphous phase, natural LECA appears with characteristic peaks of quartz, anorthite, calcite and dolomite can be seen amongst the crystalline phases presented in the samples [15]. Anorthite is the calcium-rich member of the plagioclase solid solution series with the ideal formula of $\mathrm{CaAl}_{2} \mathrm{Si}_{2} \mathrm{O}_{8}$. [16].

As it can be seen, the XRD patterns of the modified adsorbents remained almost intact showing that the modification processes did not have any impact on the overall crystalline phases of the natural LECA materials. According to XRD patterns, the most mineral phase that contain $\mathrm{Ca}$ and $\mathrm{Mg}$ are most likely responsible for the adsorption including calcite $\left(\mathrm{CaCO}_{3}\right)$; anorthite $\left(\mathrm{CaAl}_{2} \mathrm{Si}_{2} \mathrm{O}_{8}\right)$ and dolomite $\left(\mathrm{CaMg}\left(\mathrm{CO}_{3}\right)_{2}\right)$.

The SEM (LEO $1450 \mathrm{VP}$, England) micrographs of the LECA samples are shown in Fig. 2a-c. While the overall morphology of the NL and its modified counterparts were similar, the HML sample showed smoother edges. Furthermore, smaller particulates can be observed in the HML and MGML, which can be attributed to the abrasion due to the $24 \mathrm{~h}$ of treatment (for modification).

Infrared (IR) spectroscopy was used as a complementary technique to XRD in order to obtain a qualitative characterization of the samples. The IR spectra were obtained in the range of 4000$450 \mathrm{~cm}^{-1}$ wavelength by means of a Bruker (VERTEX 70, Germany). The Fourier transform infrared (FTIR) spectrometer was equipped with a $4 \mathrm{~cm}^{-1}$ resolution and worked in transmission mode using spectroscopic grade $\mathrm{KBr}$ pellets. The samples were prepared as pressed $\mathrm{KBr}$ disks and the obtained FTIR spectra are displayed in Fig. 3a-c. The presence of a strong broad in-plane bending and stretching vibrations at about $1066 \mathrm{~cm}^{-1}$ illustrated the existence of $\mathrm{Si}-\mathrm{O}-\mathrm{Si}$ bonds (siloxane groups). Bending and stretching modes of absorbed water molecules in the NL sample appeared at 3451 and $1640 \mathrm{~cm}^{-1}$, respectively. The corresponding peaks of HML and MGML appeared at slightly lower wavelengths, 3444 and $1639 \mathrm{~cm}^{-1}$ (for HML) and 3419 and $1635 \mathrm{~cm}^{-1}$ (for MGML), respectively. Furthermore, a band at $3600-3650 \mathrm{~cm}^{-1}$ can be attributed to the stretching mode of the hydroxyl groups [17]. These $-\mathrm{OH}$ groups get transformed into $-{ }^{+} \mathrm{OH}_{2}$ under acidic conditions and developed an affinity over fluoride ions in solution.

The absorption band at $1640 \mathrm{~cm}^{-1}$ can be assigned to the $\mathrm{H}-\mathrm{O}-$ $\mathrm{H}$ bending vibrations of water molecules adsorbed on the $\mathrm{NL}$ sample. The intensity and the location of this band slightly
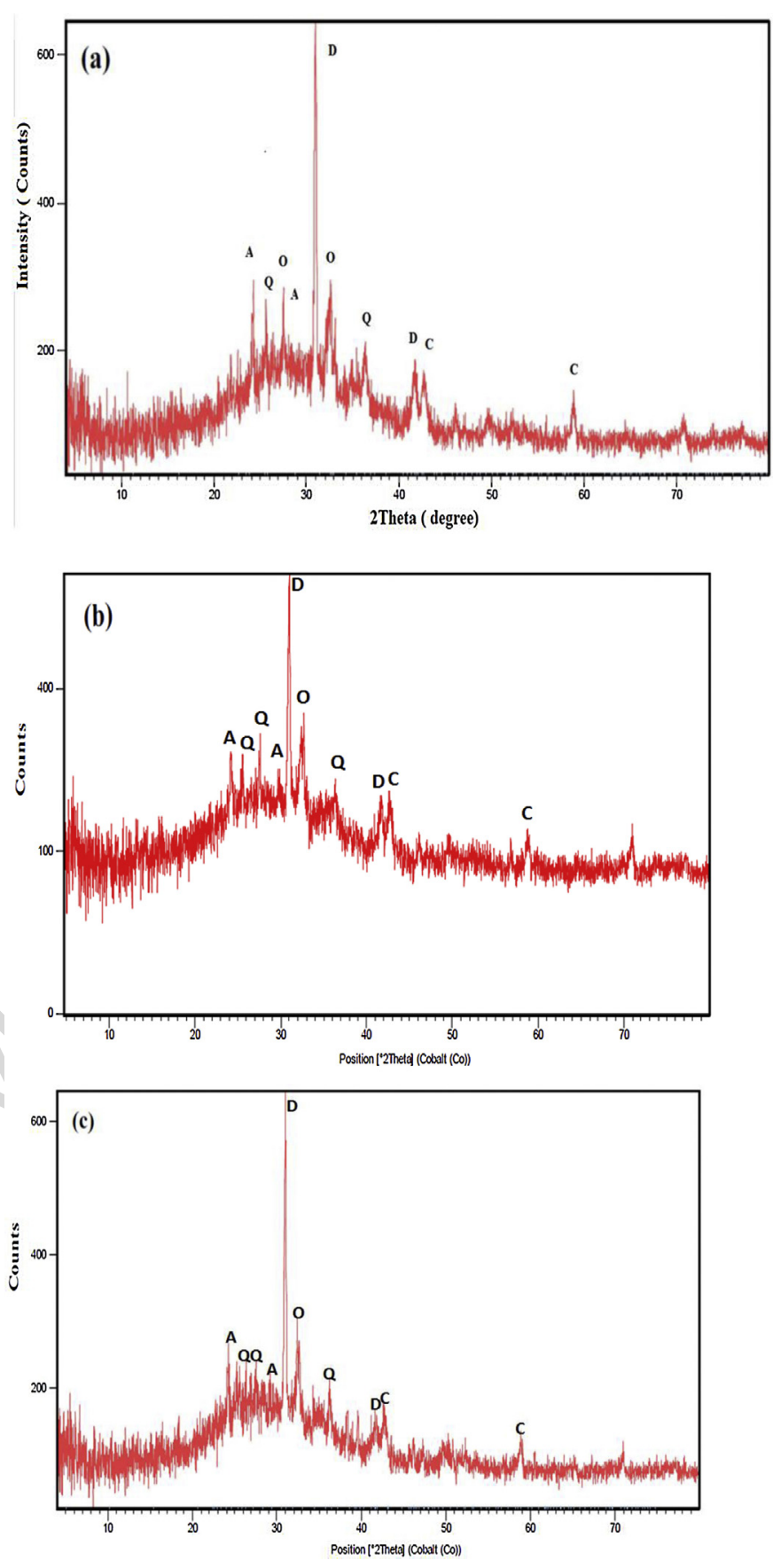

Fig. 1. XRD patterns of (a) natural LECA, (b) $\mathrm{H}_{2} \mathrm{O}_{2}$-modified LECA and (c) $\mathrm{MgCl}_{2}$ modified LECA[Q - quartz $\left(\mathrm{SiO}_{2}\right) ; \mathrm{O}$ - orthoclase $\left(\mathrm{KAlSi}_{3} \mathrm{O}_{8}\right) ; \mathrm{C}$ - calcite $\left(\mathrm{CaCO}_{3}\right)$; A - anorthite $\left(\mathrm{CaAl}_{2} \mathrm{Si}_{2} \mathrm{O}_{8}\right) ; \mathrm{D}$ - dolomite $\left.\left(\mathrm{CaMg}\left(\mathrm{CO}_{3}\right)_{2}\right)\right]$.

changed in the HML and MGML samples that can be attributed to the $\mathrm{H}_{2} \mathrm{O}$ content of the samples due to the modification process. The decrease in the intensity of the band at $1066 \mathrm{~cm}^{-1}$ (with respect to symmetry of the surface $\mathrm{Si}-\mathrm{O}-\mathrm{Si}$ vibration) may be due to the effect of modification of LECA which develops perturbation in the electric field near by the Si groups due to more positively charged groups at the proximity [18]. Nevertheless, the sharp band observed at $461 \mathrm{~cm}^{-1}$ can be considered as the fundamental $v_{1}$, and can be easily attributed to the presence of a quartz phase [19]. 

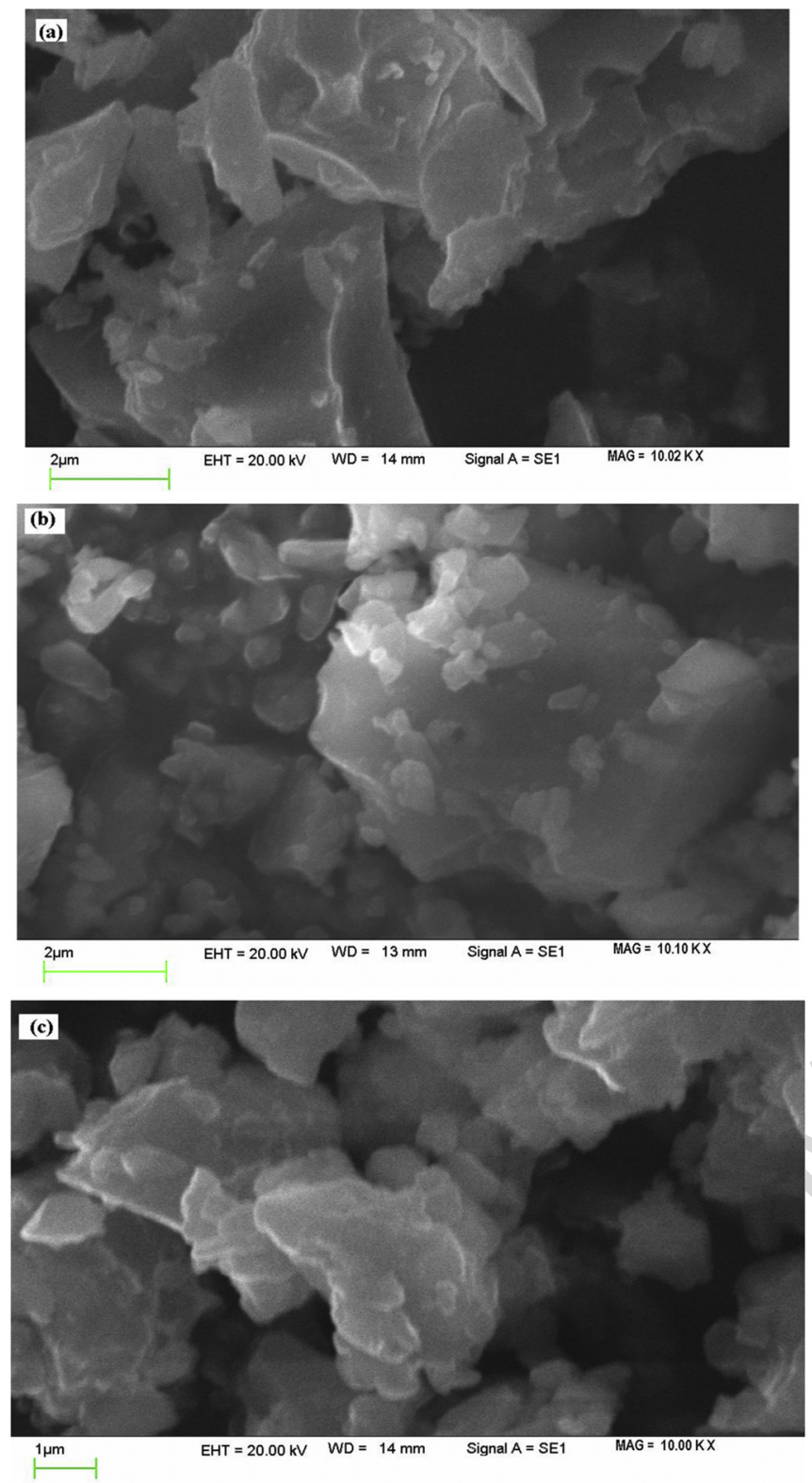

Fig. 2. SEM images of (a) Natural LECA, (b) $\mathrm{H}_{2} \mathrm{O}_{2}$-modified LECA and (c) $\mathrm{MgCl}_{2}$ modified LECA.

\subsection{Influence of the contact time and the initial fluoride concentration}

The effect of the contact time and the initial fluoride concentration on the removal efficiency is shown in Fig. 4a-c. As can be seen, fluoride uptake in initial stage was high for all adsorbents and the highest sorption rate was observed for the $\mathrm{MgCl}_{2}$ modified adsorbent. Rapid sorption of solute at initial stage is considered as a helpful adsorbent property for practical use. Removal of fluoride increased for increasing contact time until reaching equilibrium after $75 \mathrm{~min}$ for all adsorbents. This duration (75 min) was therefore considered thereafter. After 75 min contact time and depending on the initial fluoride concentration, about 68 $87 \%, 72-89$ and $74-93 \%$ of fluoride were removed by natural, $\mathrm{H}_{2} \mathrm{O}_{2}-$ and $\mathrm{MgCl}_{2}$-modified LECA, respectively. Following removal percentage, sorption capacity also increased for increasing initial fluoride concentration, from 1.23 to $2.06 \mathrm{mg} / \mathrm{g}, 2.37$ to $2.43 \mathrm{mg} / \mathrm{g}$ and 2.43 to $3.03 \mathrm{mg} / \mathrm{g}$ for initial fluoride concentrations increasing from 5 to $20 \mathrm{mg} / \mathrm{L}$ for natural, $\mathrm{H}_{2} \mathrm{O}_{2^{-}}$and $\mathrm{MgCl}_{2}$-modified LECA, respectively. This may be due to an increase in the driving force
Table 2

Parameters collected from kinetic models.

\begin{tabular}{|c|c|c|c|c|c|}
\hline \multicolumn{6}{|l|}{ Fluoride concentration } \\
\hline & Parameters & $5 \mathrm{mg} / \mathrm{L}$ & $10 \mathrm{mg} / \mathrm{L}$ & $15 \mathrm{mg} / \mathrm{L}$ & $20 \mathrm{mg} / \mathrm{L}$ \\
\hline \multicolumn{6}{|l|}{ Natural LECA } \\
\hline \multirow[t]{4}{*}{ Pseudo-first order } & $k_{1}$ & 0.026 & 0.025 & 0.023 & 0.021 \\
\hline & $q_{\mathrm{e}, \text { calc }}$ & 0.69 & 1.51 & 2.33 & 3.13 \\
\hline & $q_{\mathrm{e}, \exp }$ & 0.68 & 1.51 & 2.31 & 3.12 \\
\hline & $R^{2}$ & 0.96 & 0.98 & 0.97 & 0.97 \\
\hline \multirow[t]{4}{*}{ Pseudo-second order } & $k_{2}$ & 0.24 & 0.21 & 0.20 & 0.17 \\
\hline & $q_{\mathrm{e}, \text { calc }}$ & 0.75 & 1.66 & 2.57 & 3.33 \\
\hline & $q_{\mathrm{e}, \exp }$ & 0.68 & 1.51 & 2.31 & 3.12 \\
\hline & $R^{2}$ & 0.997 & 0.994 & 0.996 & 0.998 \\
\hline \multirow{4}{*}{$\begin{array}{l}\text { Modified pseudo-first } \\
\text { order }\end{array}$} & $k_{\mathrm{m}}$ & 0.017 & 0.021 & 0.025 & 0.025 \\
\hline & $q_{\mathrm{e}, \text { calc }}$ & 0.69 & 1.53 & 2.31 & 3.13 \\
\hline & $q_{\mathrm{e}, \exp }$ & 0.68 & 1.51 & 2.31 & 3.12 \\
\hline & $R^{2}$ & 0.98 & 0.99 & 0.97 & 0.98 \\
\hline \multicolumn{6}{|l|}{$\mathrm{H}_{2} \mathrm{O}_{2}$ modified LECA } \\
\hline \multirow[t]{4}{*}{ Pseudo-first order } & $k_{1}$ & 0.027 & 0.026 & 0.023 & 0.021 \\
\hline & $q_{\mathrm{e}, \text { calc }}$ & 0.81 & 1.580 & 2.41 & 3.22 \\
\hline & $q_{\mathrm{e}, \exp }$ & 0.79 & 1.578 & 2.40 & 3.21 \\
\hline & $R^{2}$ & 0.97 & 0.95 & 0.95 & 0.94 \\
\hline \multirow[t]{4}{*}{ Pseudo-second order } & $k_{2}$ & 0.28 & 0.21 & 0.17 & 0.17 \\
\hline & $q_{\mathrm{e}, \text { calc }}$ & 0.84 & 1.70 & 2.50 & 3.34 \\
\hline & $q_{\mathrm{e}, \exp }$ & 0.79 & 1.59 & 2.40 & 3.20 \\
\hline & $R^{2}$ & 0.99 & 0.99 & 0.99 & 0.99 \\
\hline \multirow{4}{*}{$\begin{array}{l}\text { Modified pseudo-first } \\
\text { order }\end{array}$} & $k_{\mathrm{m}}$ & 0.015 & 0.025 & 0.024 & 0.025 \\
\hline & $q_{\mathrm{e}, \text { calc }}$ & 0.8 & 1.61 & 2.43 & 3.22 \\
\hline & $q_{\mathrm{e}, \exp }$ & 0.79 & 1.59 & 2.40 & 3.20 \\
\hline & $R^{2}$ & 0.97 & 0.95 & 0.96 & 0.93 \\
\hline \multicolumn{6}{|c|}{$\mathrm{MgCL}_{2}$ modified LECA } \\
\hline \multirow[t]{4}{*}{ Pseudo-first order } & $k_{1}$ & 0.029 & 0.027 & 0.024 & 0.022 \\
\hline & $q_{\mathrm{e}, \text { calc }}$ & 0.712 & 1.533 & 2.351 & 3.14 \\
\hline & $q_{\mathrm{e}, \exp }$ & 0.71 & 1.53 & 2.35 & 3.13 \\
\hline & $R^{2}$ & 0.96 & 0.97 & 0.97 & 0.98 \\
\hline \multirow[t]{4}{*}{ Pseudo-second order } & $k_{2}$ & 0.25 & 0.23 & 0.19 & 0.16 \\
\hline & $q_{\mathrm{e}, \text { calc }}$ & 0.8 & 1.68 & 2.53 & 3.3 \\
\hline & $q_{\mathrm{e}, \exp }$ & 0.71 & 1.53 & 2.35 & 3.13 \\
\hline & $R^{2}$ & 0.99 & 0.99 & 0.99 & 0.99 \\
\hline \multirow{4}{*}{$\begin{array}{l}\text { Modified pseudo-first } \\
\text { order }\end{array}$} & $k_{\mathrm{m}}$ & 0.013 & 0.014 & 0.013 & 0.017 \\
\hline & $q_{\mathrm{e}, \text { calc }}$ & 0.712 & 1.532 & 2.351 & 3.137 \\
\hline & $q_{\mathrm{e}, \exp }$ & 0.71 & 1.53 & 2.35 & 3.13 \\
\hline & $R^{2}$ & 0.98 & 0.98 & 0.97 & 0.96 \\
\hline
\end{tabular}

with increasing initial solute concentration. For a given mass of adsorbent, the active sites for sorption of solute are fixed; therefore sorption capacity may decrease for increasing initial solute concentration [8]. However, in the present work, for a given mass of adsorbent, the sorption capacity increased for increasing fluoride concentrations, showing that the internal part of the adsorbent was also used for fluoride sorption. On the other hand, the sorption rate, $k_{2}$ (Table 2) decreased for increasing fluoride concentrations, showing that penetration of fluoride onto internal part of adsorbent was slower than on the surface part.

Many researchers have tested various adsorbent for fluoride removal. In the removal of fluoride by orange waste gel loaded with some earth ions, $3 \mathrm{~h}$ contact time was reported to be optimal for sorption capacity [20], and using hydrous zirconium oxide, $200 \mathrm{~min}$ was needed for equilibrium [21]. It was also reported that $10 \mathrm{~h}$ contact time are needed in the removal of fluoride by granular ferric hydroxide to reach equilibrium [22]. In all cases and in agreement with our findings, sorption capacity increased with increasing fluoride concentration [20-22].

The mechanism of adsorption (such as chemical reaction, diffusion control and mass transfer) was determined from kinetic models, and hence time-concentration profiles of the sorption of fluoride by natural and modified LECA adsorbents were analyzed by pseudo-first order, pseudo-second order and modified pseudofirst order kinetic models. As can be seen from Table 2, equilibrium data were accurately fitted onto all kinetic models; however and since the pseudo second order kinetic model led to the highest 

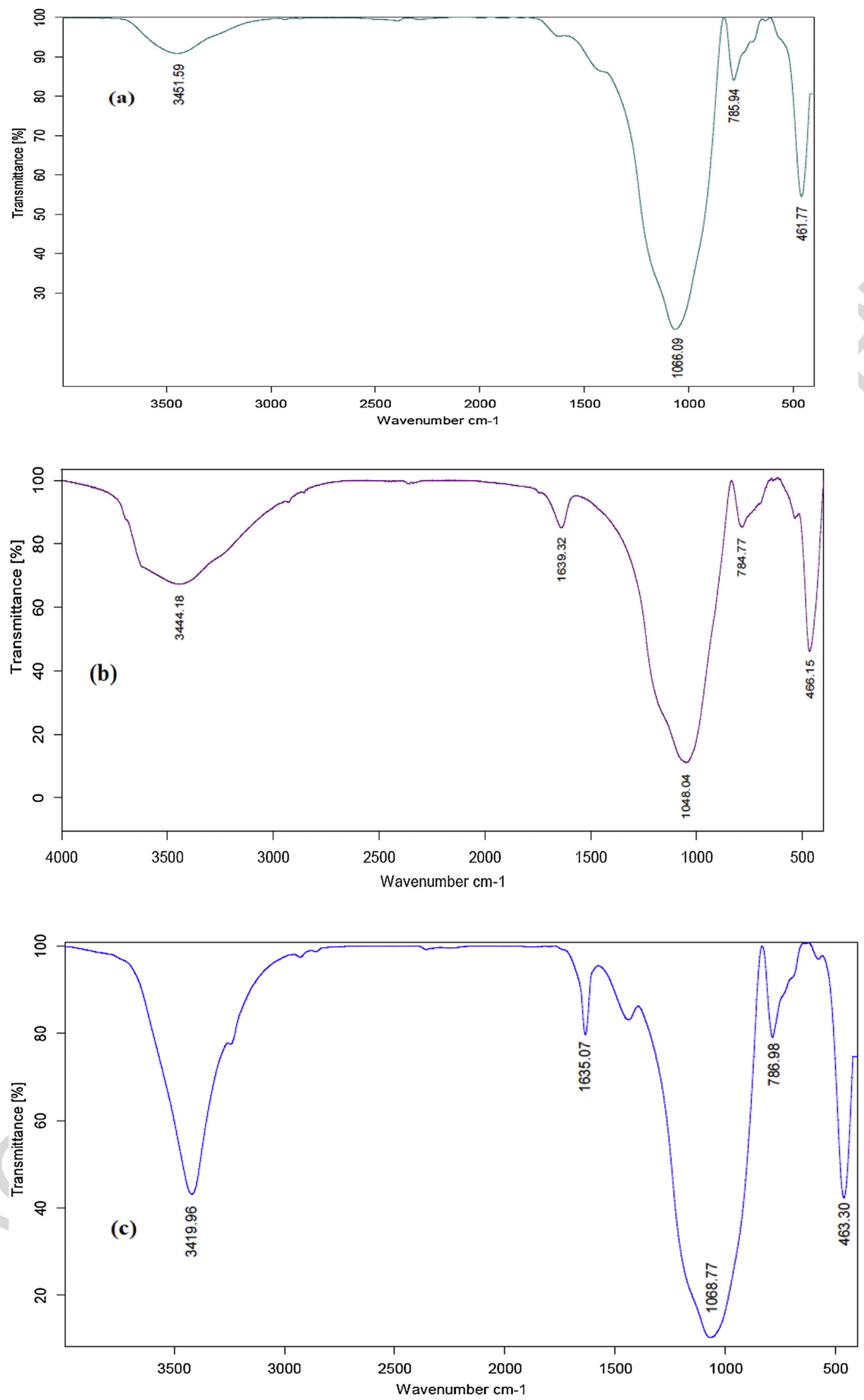

Fig. 3. FTIR spectra of (a) Natural LECA, (b) $\mathrm{H}_{2} \mathrm{O}_{2}$-modified LECA and (c) $\mathrm{MgCl}_{2}$-modified LECA. 

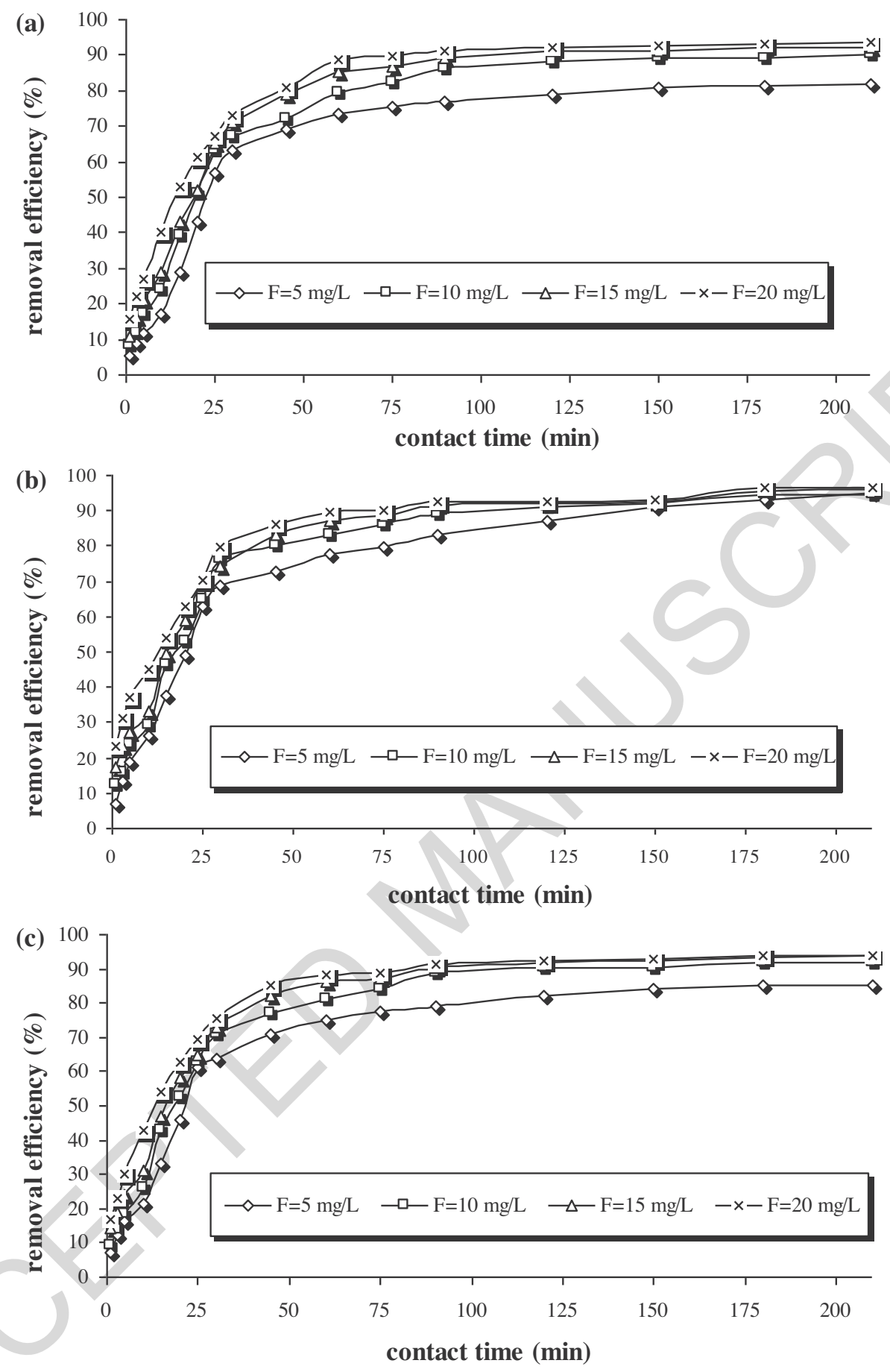

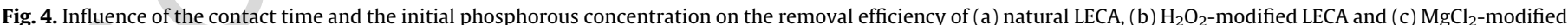
LECA (conditions: pH 5.5; dose $-6 \mathrm{~g} / \mathrm{L}$; stirring rate $-200 \mathrm{rpm}$; temperature $-20^{\circ} \mathrm{C}$ ).

correlation coefficient, only pseudo-second order kinetic results are shown and the related parameters are collected in Table 2.

For the three kinetic models, the standard error was in the range 0.02-0.2 (Table 2), confirming the closeness between experimental and calculated $\mathrm{q}_{\mathrm{e}}$ values. For initial fluoride concentration in the range $5-20 \mathrm{mg} / \mathrm{L}$, the sorption rate by pseudo-first order model for natural, $\mathrm{H}_{2} \mathrm{O}_{2}$ - and $\mathrm{MgCl}_{2}$-modified LECA was found in the range 0.026-0.021 $\mathrm{min}^{-1}, \quad 0.027-0.021 \mathrm{~min}^{-1}$ and $0.029-0.022 \mathrm{~min}^{-1}$ respectively (Table 2 ). If sorption kinetics obeys to pseudo-firstorder model, the variation in $k_{1}$ with initial concentration should increase linearly with increasing initial concentration [23], as shown(Fig. 5a-c) for the first-order rate constants, $R^{2}=0.98,0.97$ and 0.99 for NL, HML and MGML, respectively. Regarding the pseudo-second order model, for initial fluoride concentration in the range $5-20 \mathrm{mg} / \mathrm{L}$, the rate constants were found to be in the ranges $0.24-17 \mathrm{~g} / \mathrm{mg} / \mathrm{min}, 0.28-17 \mathrm{~g} / \mathrm{mg} / \mathrm{min}$ and $0.25-16 \mathrm{~g} / \mathrm{mg} /$ min for natural, $\mathrm{H}_{2} \mathrm{O}_{2}$ and $\mathrm{MgCl}_{2}$ modified LECA respectively. Contrarily to the pseudo-first order model, the pseudo-second order rate constant is not necessarily linearly linked to the initial solute concentration [23]. However, the pseudo-second order rate constant was found to linearly decrease with increasing initial fluoride amount. For initial fluoride concentration in the range 5$20 \mathrm{mg} / \mathrm{L}$, the rate constants for modified pseudo-second order model were found to increase with fluoride concentration and 


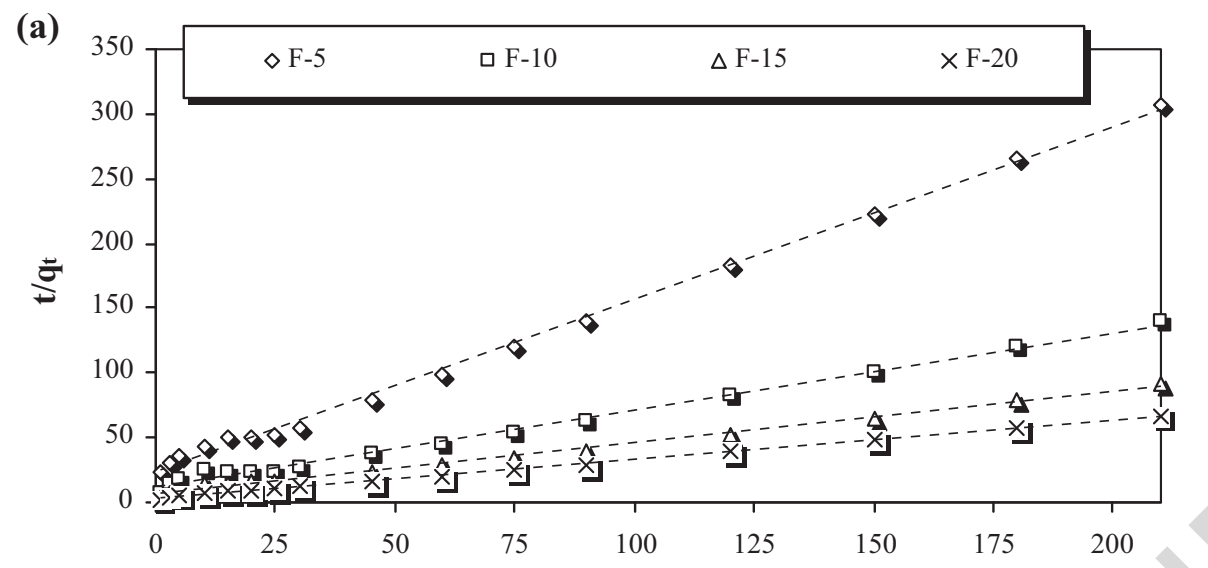

time (min)
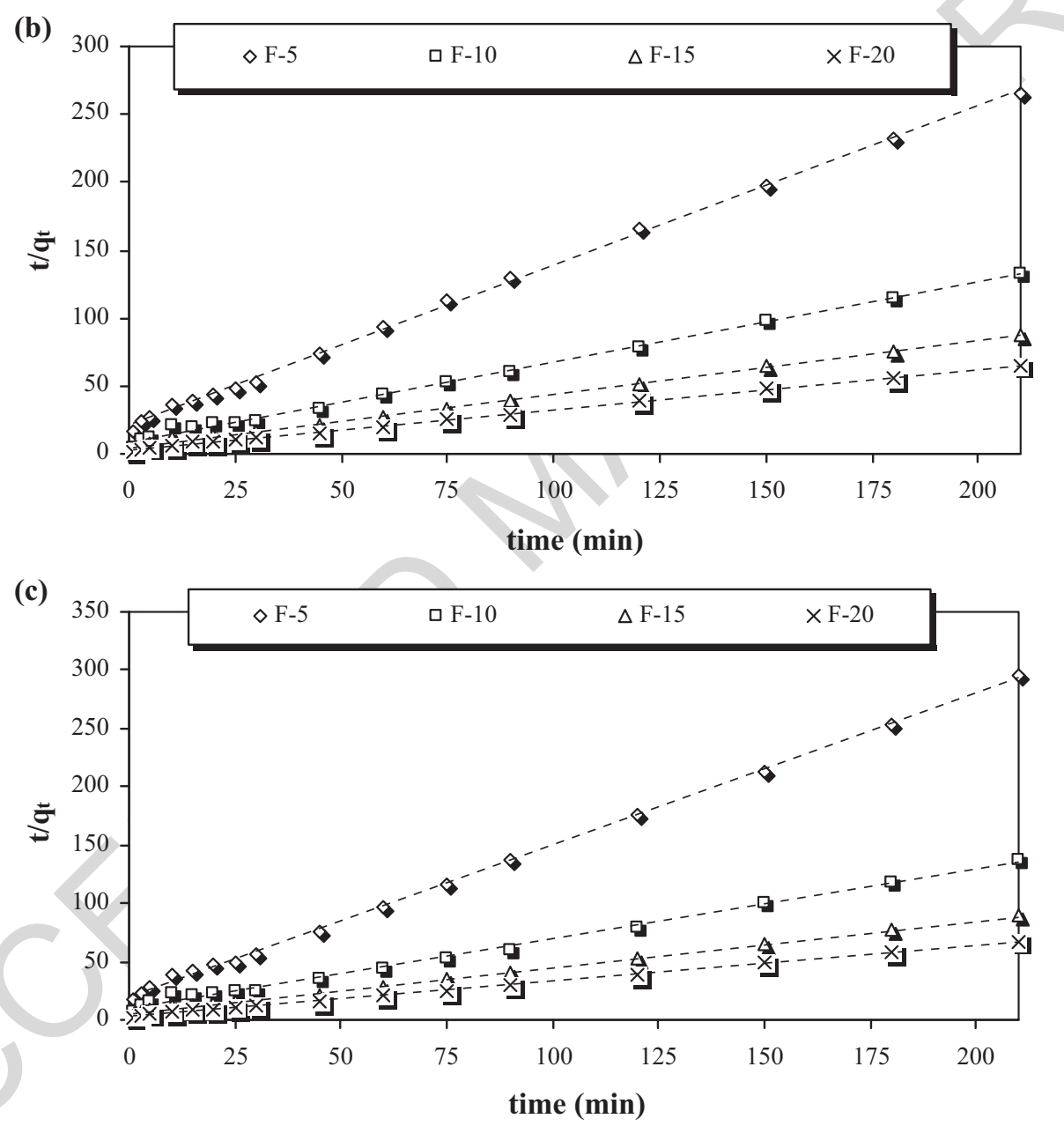

Fig. 5. Pseudo-second order kinetic model for (a) natural LECA, (b) $\mathrm{H}_{2} \mathrm{O}_{2}$-modified LECA and (c) $\mathrm{MgCl}_{2}$-modified LECA.

were in the range $0.017-0.024 \mathrm{~min}^{-1}, 0.015-0.028 \mathrm{~min}^{-1}$ and 0.013-0.017 $\mathrm{min}^{-1}$ for natural, $\mathrm{H}_{2} \mathrm{O}_{2}$ and $\mathrm{MgCl}_{2}$ modified LECA, respectively.

\subsection{Influence of the $\mathrm{pH}$}

The role of $\mathrm{pH}$ is significant in the control of the surface charge of the adsorbent and in the removal of the adsorbate from the solution. Therefore, its effect on fluoride adsorption was examined (Fig. 6a). Maximum fluoride sorption occurred for $\mathrm{pH}$ in the range
5.5-6.3. Maximum fluoride removal yields at $\mathrm{pH} 6$ were $79.4 \%$, 83.0\% and $81.2 \%$ for natural, $\mathrm{H}_{2} \mathrm{O}_{2}$ - and $\mathrm{MgCl}_{2}$-modified LECA, respectively. Therefore and surprisingly, LECA adsorbents exhibited relatively high sorption capacities for fluoride anion near its natural $\mathrm{pH}$. The higher point of zero charge (PZC) of LECA (5.5-6 depending of the used adsorbent), leading to a more extensive protonation of its surface at the working $\mathrm{pH}$ conditions ( $\mathrm{pH}$ 5.5) can account, at least partially, for this behavior. At these $\mathrm{pH}$ values, the adsorbents surfaces are positively charged. In this case, it can be considered that adsorption is mainly controlled by the combined 

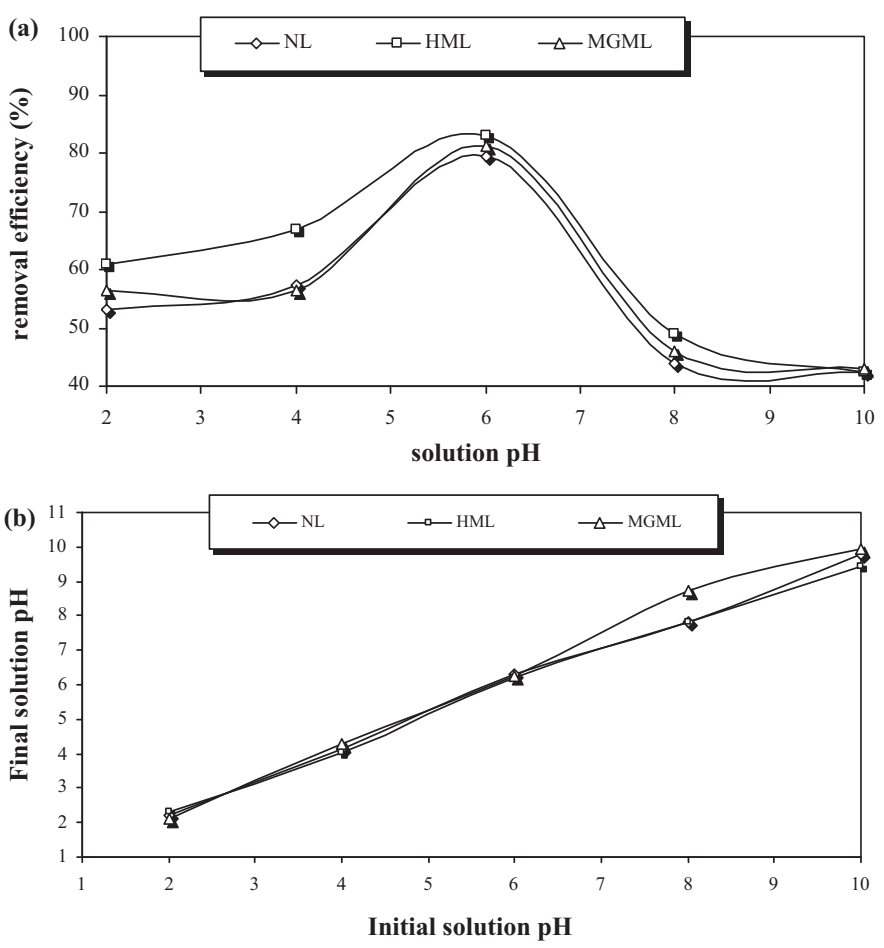

Fig. 6. (a) Effect of $\mathrm{pH}$ on fluoride removal and (b) variation in final solution $\mathrm{pH}$ (conditions: fluoride concentration - $10 \mathrm{mg} / \mathrm{L}$; dose $-6 \mathrm{~g} / \mathrm{L}$; contact time - $75 \mathrm{~min}$; stirring rate - $200 \mathrm{rpm}$; temperature $-20^{\circ} \mathrm{C}$.

effects of chemical and electrostatic interactions between the oxide surface and the fluoride ions in solution, as well as by the availability of active sites on the oxide surfaces [14]. The anionic or $\mathrm{H}_{2} \mathrm{O}$ displacement on the metal oxide surface through columbic forces and/or ligand exchange may be attributed to the fluoride removal of the present system. Fluoride uptake capacity of the three LECA adsorbents decreased in $\mathrm{pH}$ ranges 2-6 and 6-10. The lower fluoride adsorption of natural, $\mathrm{H}_{2} \mathrm{O}_{2}$ - and $\mathrm{MgCl}_{2}$-modified LECA below pH 6 may be attributed to the competition between adsorption behavior and the formation of hydrofluoric acid. According to the fluoride speciation, hydrogen fluoride was predominant at $\mathrm{pH}$ less than 3.18 [24]. On the other hand, the decrease in fluoride removal under alkaline conditions may be due to the competition of excess hydroxyl ions with fluoride ions for active sites on the used adsorbents [25]. The change in final $\mathrm{pH}$ (Fig.6b) in the present work was in agreement with other findings, such as the removal of fluoride with hydrous manganese oxidecoated alumina [26] and carboxylated aerobic granules containing Ce(III) [27].

The optimal pH found in this work (6) was in agreement with the reported optimal $\mathrm{pH}$ (in the range 5-7), as shown for the removal of fluoride by $\mathrm{La}^{3+}$ impregnated cross-linked gelatin [28]. Using $\mathrm{Fe}(\mathrm{III})$-loaded ligand exchange cotton cellulose adsorbent, optimal fluoride sorption was observed at $\mathrm{pH} 4$, while fluoride removal was not significantly affected in the $\mathrm{pH}$ range 4-9 [29]. $\mathrm{pH}$ in the range 4-7 and 3-6.5 were found to be optimal for the removal of fluoride by activated alumina and manganese-oxide-coated alumina [30] and by granular ferric hydroxide [22]. Therefore, fluoride removal driven by acidic environment appears to be suitable for the present sorption system.

In the fluoride sorption process, the essential participation of interactive oxide surface with active sites and prioritization of anionic displacement through columbic forces are also associated. The columbic interaction is also acknowledged from $\equiv \mathrm{Si}^{+}$and $\mathrm{Si}-$ $\mathrm{OH}_{2}{ }^{+}$species [31] resulting from bond breaking or deprotonation of $\equiv \mathrm{Si}-\mathrm{OH}$ groups on the surface of LECA particles.

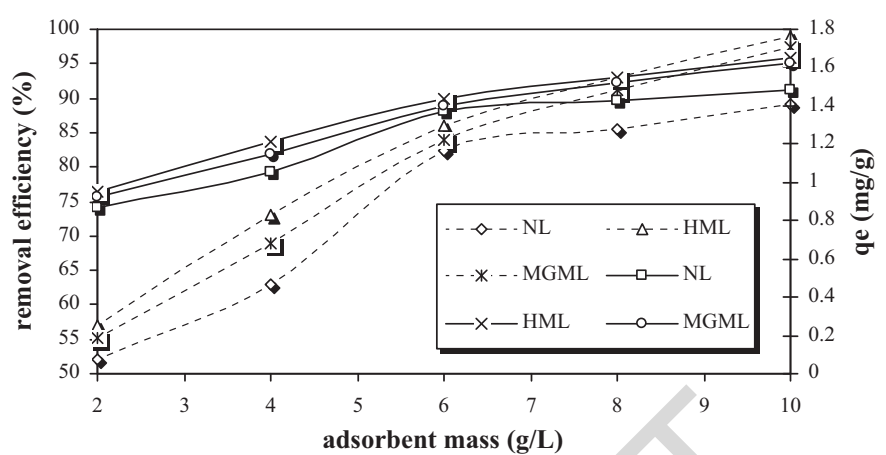

Fig. 7. Effect of adsorbent dosage on sorption yield (conditions: $\mathrm{pH}$ 5.5; fluoride concentration - $10 \mathrm{mg} / \mathrm{L}$; contact time - $75 \mathrm{~min}$; stirring rate - $200 \mathrm{rpm}$; temperature $-20^{\circ} \mathrm{C}$ ).

The predicted mechanism for the adsorption of fluoride under acidic conditions is mainly corroborated as follows (15).

$$
\begin{aligned}
\equiv & \mathrm{MOH}+\mathrm{H}_{2} \mathrm{O}+\mathrm{F}^{-} \leftrightarrow \mathrm{MOH}_{2}^{+}+\mathrm{F}^{-}+\mathrm{OH}^{-} \leftrightarrow \mathrm{MOH}_{2}^{+} \ldots \mathrm{F}^{-} \\
& +\mathrm{OH}^{-} \leftrightarrow \mathrm{M}-\mathrm{F}+\mathrm{H}_{2} \mathrm{O}+\mathrm{OH}^{-}
\end{aligned}
$$

Similar studies conducted on fluoride sorption at acidic $\mathrm{pH}$ range were reported in literatures [32,33].

\subsection{Influence of the adsorbent dosage}

The influence of the adsorbent dosage was studied in the range 2-10 $\mathrm{g} / \mathrm{L}$ for the three adsorbents and results are shown in Fig. 7. Removal efficiency increased with the mass of adsorbent and hence the higher percentage was observed for $10 \mathrm{~g} / \mathrm{L}$ adsorbent. At $\mathrm{pH} 5.5$, for increasing adsorbent mass from 2 to $10 \mathrm{~g} / \mathrm{L}$, removal efficiency increased from 52 to $89 \%, 57$ to $99 \%$ and 55.3 to $97.4 \%$ for natural, $\mathrm{H}_{2} \mathrm{O}_{2}$ - and $\mathrm{MgCl}_{2}$-modified LECA respectively, in agreement with an increase in active sites for a higher amount of adsorbent. In close relation with the increase of sorption yields, adsorption capacity also increased from 0.86 to $1.50 \mathrm{mg} / \mathrm{g}, 0.97$ to $1.71 \mathrm{mg} / \mathrm{g}$ and 0.92 to $1.62 \mathrm{mg} / \mathrm{g}$ for natural, $\mathrm{H}_{2} \mathrm{O}_{2^{-}}$and $\mathrm{MgCl}_{2^{-}}$ modified LECA, respectively. The linear increase of the adsorption capacity for increasing adsorbent dosage indicated the accessibility of a larger number of sorption sites at higher dosage to adsorb fluoride ions.

\subsection{Influence of the temperature}

The temperature effect in the range $20-60{ }^{\circ} \mathrm{C}$ was examined and thermodynamic parameters were calculated and summarized in Table 3. As shown in Fig. 8a, while the effect of temperature on fluoride adsorption onto $\mathrm{H}_{2} \mathrm{O}_{2}$ - and $\mathrm{MgCl}_{2}$-modified LECA seemed to be negligible, a lower maximum fluoride adsorption onto natural LECA was observed at $60{ }^{\circ} \mathrm{C}$.

The Arrhenius equation was used to evaluate the nature of the adsorption (either physical $(5-40 \mathrm{~kJ} / \mathrm{mol})$ or chemical $(40-800 \mathrm{~kJ} /$ mol):

$$
\ln k_{\mathrm{d}}=\ln A_{0}-\frac{E_{\mathrm{a}}}{\mathrm{RT}}
$$

where $A_{o}$ is the temperature independent factor called "frequency factor," $E_{\mathrm{a}}$ the activation energy $(\mathrm{kJ} / \mathrm{mol}), R$ is the gas

Table 3

Thermodynamic parameters for the three adsorbents.

\begin{tabular}{lrlrrrrr}
\hline \multicolumn{1}{c}{$\Delta H^{\circ}$} & $\Delta S^{\circ}$ & \multicolumn{1}{l}{$\Delta G^{\circ}$} \\
\hline$T(K)$ & & & 293 & 303 & 313 & 323 & 333 \\
NL & -16719 & -58.88 & -621.1 & -989.8 & -1663.1 & -2335.3 & -2962.3 \\
HML & -6447 & -22.15 & -42.4 & -260.7 & -499.4 & -703.1 & -928.1 \\
MGML & -7688 & -27.23 & -325.3 & -554.8 & -803.9 & -1038.2 & -1456.5 \\
\hline
\end{tabular}



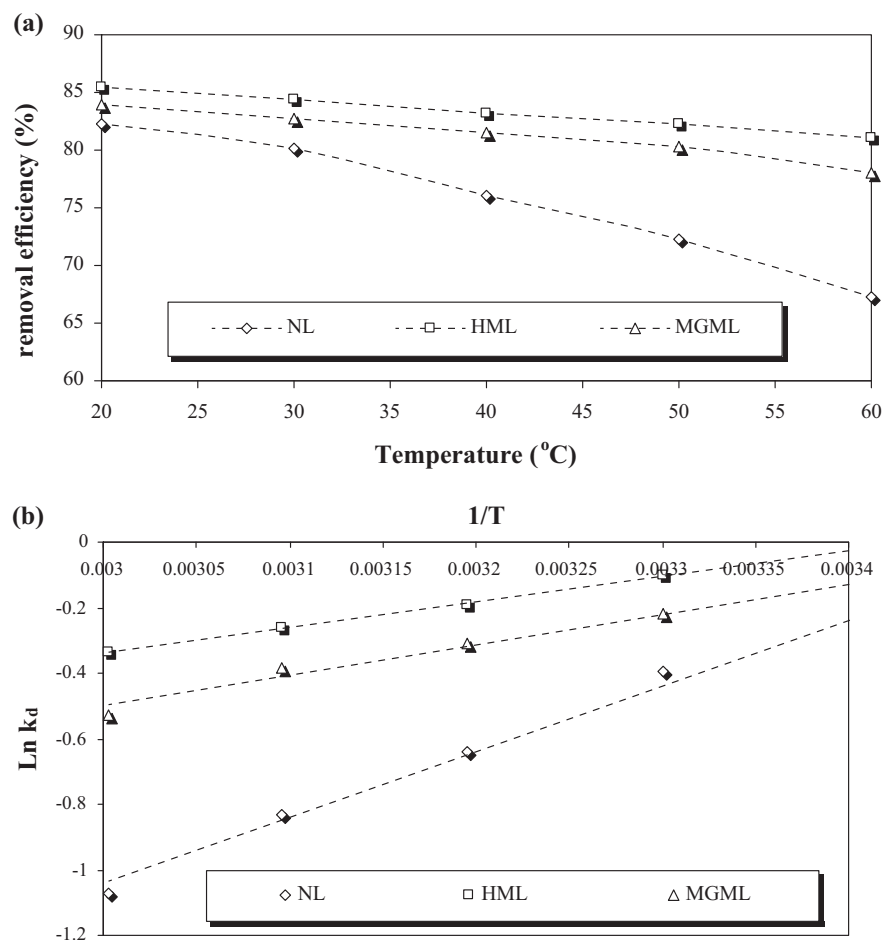

Fig. 8. Effect of the temperature on fluoride adsorption (Conditions: $\mathrm{pH}$ 5.5; fluoride concentration - $10 \mathrm{mg} / \mathrm{L}$; contact time - $75 \mathrm{~min}$; stirring rate $-200 \mathrm{rpm}$ ).

law constant $(8.314 \mathrm{~J} / \mathrm{mol} / \mathrm{K})$, and $T$ is the absolute temperature $(K)$. A plot of $\ln k$ versus $1 / T$ yields to a straight line, from which the $E_{\mathrm{a}}$ and $A_{\mathrm{o}}$ can be obtained from the slope and the intercept, respectively. In the present work, the value of $E_{\mathrm{a}}$ was observed to be $85.89 \mathrm{~kJ} / \mathrm{mol}, 27.23 \mathrm{~kJ} / \mathrm{mol}$ and $22.15 \mathrm{~kJ} / \mathrm{mol}$ for natural, $\mathrm{H}_{2} \mathrm{O}_{2}$ - and $\mathrm{MgCl}_{2}$-modified LECA respectively, indicating chemical adsorption rather than physisorption for adsorption of fluoride onto natural LECA, while onto $\mathrm{H}_{2} \mathrm{O}_{2}$ - and $\mathrm{MgCl}_{2}$-modified LECA physisorption mechanism, involving weak interactions (i.e., hydrogen bonding) between the adsorbent and the sorbate was shown.

Thermodynamic parameters were determined for temperatures ranging from 20 to $60{ }^{\circ} \mathrm{C}$ using the equilibrium constant $k_{\mathrm{d}}\left(q_{\mathrm{e}} / C_{\mathrm{e}}\right)$. The change in free energy $\left(\Delta G^{\circ}\right)$ was determined from the following Eq. (17):

$\Delta G^{0}=-\mathrm{RT} \ln K_{\mathrm{d}}$

where, $\Delta G^{\circ}$ is the standard free energy $(\mathrm{kJ} / \mathrm{mol})$. The parameters of enthalpy $\Delta \mathrm{H}^{\circ}(\mathrm{kJ} / \mathrm{mol})$ and entropy $\Delta S^{\circ}(\mathrm{kJ} / \mathrm{mol})$ related to the adsorption process were calculated from the following Eq. (18):

$\ln K_{\mathrm{d}}=\frac{\Delta S^{0}}{R}-\frac{\Delta H^{0}}{\mathrm{RT}}$

The parameters of enthalpy $\left(\Delta H^{\circ}\right)$ and entropy $\left(\Delta S^{\circ}\right)$ can be calculated from the slope and the intercept of the linear plot of $\ln k_{\mathrm{d}}$ versus $1 / T$. Fig. 8 shows the thermodynamic plots and the related parameters are collected in Table 3. The values of $\Delta H^{\circ}$ were negative for all systems; showing that the sorption reaction was exothermic in nature. The negative $\Delta S^{\circ}$ value characterized a decrease in randomness at the solid/liquid interface during the sorption process. In addition, the values of standard free energy $\left(\Delta G^{\circ}\right)$ were negative indicating that the sorption was not thermodynamically spontaneous. The negative $\Delta G^{\circ}$ values increased with respect to the increase in temperature from 293 to $333 \mathrm{~K}$.
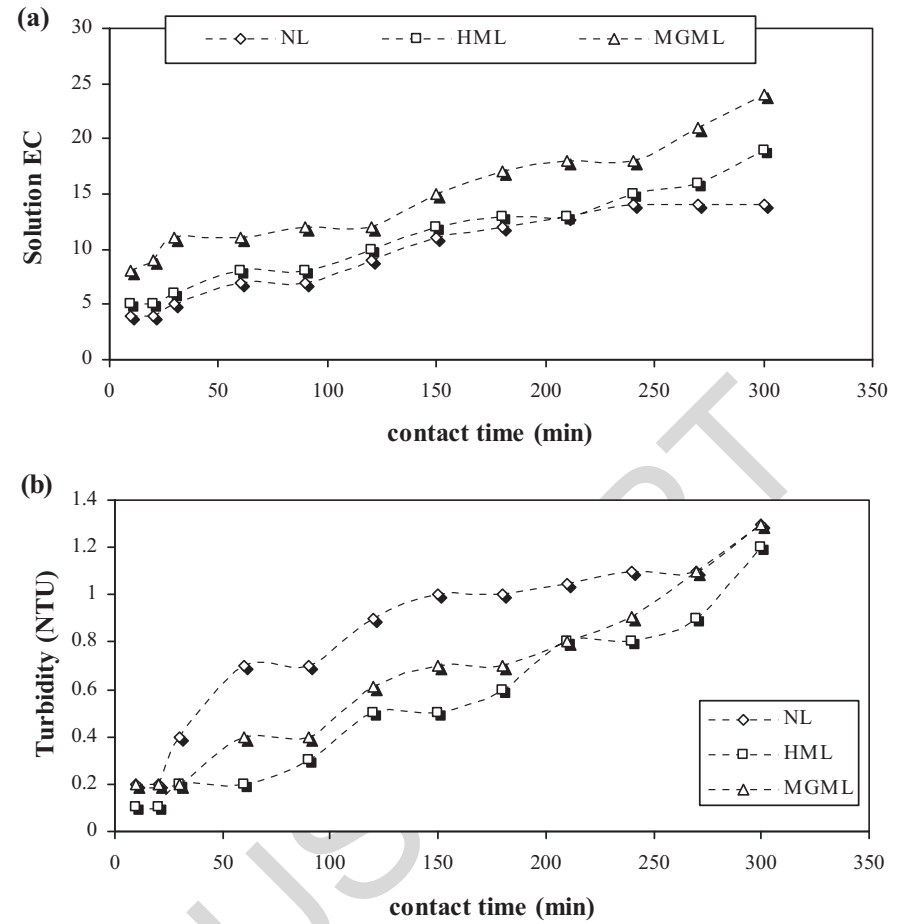

Fig. 9. Influence of the adsorbents on (a) conductivity and (b) turbidity of a water sample (conditions: $\mathrm{pH} 7.0$; contact time - $200 \mathrm{~min}$; stirring rate - $200 \mathrm{rpm}$ ).

\subsection{Influence of the adsorbent on conductivity (EC) and turbidity}

Partial dissolution of adsorbent in the surrounding solution may have an impact on the adsorption process impacting ions uptake capacity. The hardness of an adsorbent is a major aspect and hence to assess for its stability in aqueous solution, the monitoring of conductivity (EC) and turbidity may be useful. The corresponding experiment was carried out using de-ionized water. As shown in Fig. 9a and b, EC and turbidity increased with time for both natural and modified LECA. EC increased from 5 to $13(\mu \mathrm{s} / \mathrm{cm}), 5$ to $17(\mu \mathrm{s} / \mathrm{cm})$ and 7 to $24(\mu \mathrm{s} / \mathrm{cm})$ for natural, $\mathrm{H}_{2} \mathrm{O}_{2}-$ and $\mathrm{MgCl}_{2}$-modified LECA respectively. This increase can be attributed to the presence of some soluble constituents from the adsorbents.

Turbidity increased from 0.2 to $1.2 \mathrm{NTU}, 0.1$ to 0.17 NTU and 0.19 to $1.22 \mathrm{NTU}$ for natural, $\mathrm{H}_{2} \mathrm{O}_{2^{-}}$and $\mathrm{MgCl}_{2}$-modified LECA respectively. However, it should be noted that such increase in EC and turbidity after 300 minute contact time appeared very low if compared with EC and turbidity in real wastewater. Therefore, the present adsorbents may have only a limited impact on the conductivity and the turbidity of aqueous solutions.

\subsection{Influence of ionic strength}

Electrolytes have an important role in solute adsorption, since it can influence the electrostatic interactions between the solute and the adsorbent on the one hand, and the surface charge of the adsorbent on the other hand. In addition, electrolyte ions may compete with solute to adsorb on the adsorbent [34]. Therefore, the ionic strength was investigated by adding 0.01, 0.02 and $0.04 \mathrm{~mol} / \mathrm{L}$ of $\mathrm{NaCl}$ in the presence of $10 \mathrm{mg} / \mathrm{L}$ fluoride concentration. As shown in Fig. 10a-c, removal efficiency decreased with an increase in ionic strength. Without the addition of $\mathrm{NaCl}$, the removal efficiencies after $120 \mathrm{~min}$ were $88.0 \%, 91.0 \%$ and $90.1 \%$ for natural, $\mathrm{H}_{2} \mathrm{O}_{2}$ - and $\mathrm{MgCl}_{2}$-modified LECA, respectively. It was in agreement with the decrease previously reported for the removal 

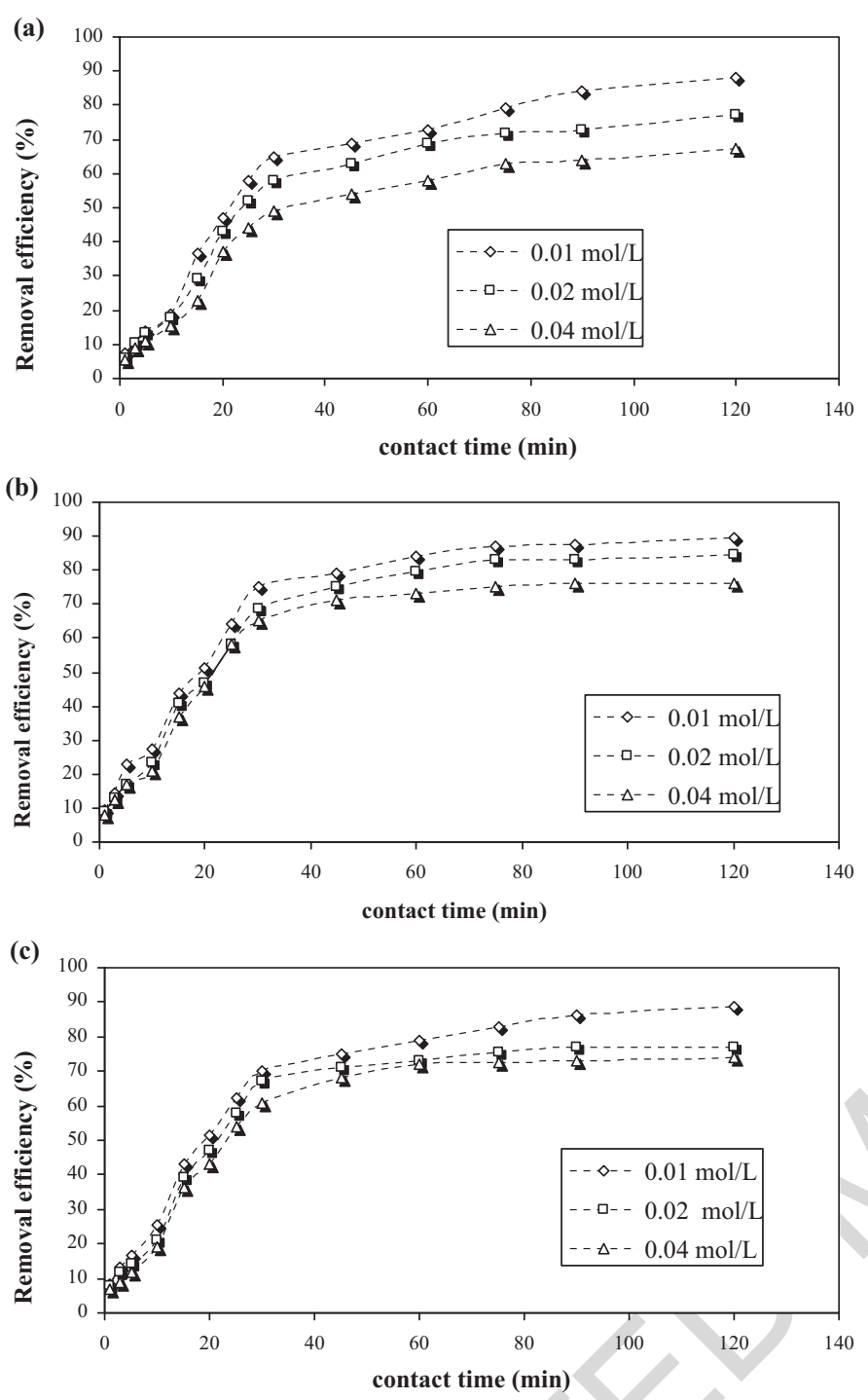

Fig. 10. Influence of ionic strength on fluoride removal efficiency by (a) natural LECA, (b) $\mathrm{H}_{2} \mathrm{O}_{2}$-modified LECA and (c) $\mathrm{MgCl}_{2}$-modified LECA(conditions: $\mathrm{pH}$ 5.5; contact time - $120 \mathrm{~min}$; stirring rate - $200 \mathrm{rpm}$;)

of fluoride by granular ferric hydroxide for increasing ionic strength [22].

In addition, the formation of inner-sphere complex or outersphere complex may influence the ions sorption rate at various ionic strengths. The former is a complex in which ligands replace water molecules from the inner coordination sphere and form bonds directly to solute ions. The latter is a complex in which there are no bonds between ligands and solute ions. For inner-sphere complex forming ions, increasing in ionic strength may increase the adsorption capacity or has no effect on adsorption capacity. On the other hand, outer-sphere complex forming ions leads to a decrease of the adsorption capacity for increasing ionic strength. The latter complex is formed mainly by electrostatic interactions and usually contains more than one water molecule between the solute and adsorbent functional groups [35]. From this and due to the decrease of the removal efficiency for increasing ionic strength, the adsorption of fluoride by the considered adsorbents was due to the formation of outer-sphere complex between fluoride and LECA (Fig.10).

It can also be noted that the decrease in the removal efficiency for increasing ionic strength was higher for natural LECA than

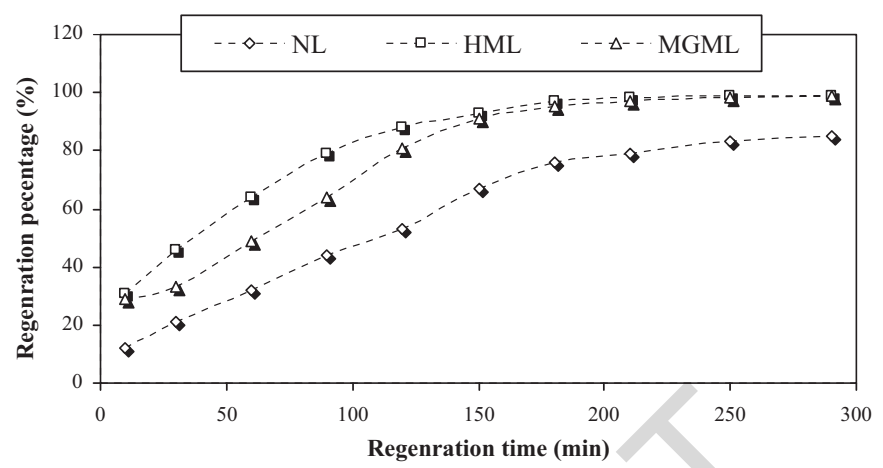

Fig. 11. Time-course of regeneration of spent adsorbents (conditions: $\mathrm{pH} 5.5$; spend adsorbent $-6 \mathrm{~g} / \mathrm{L}$; contact time - $300 \mathrm{~min}(\mathrm{NL}), 180 \mathrm{~min}$ (HML, MGML); stirring rate - $200 \mathrm{rpm})$.

modified LECA. This phenomenon may be due to competing effect of $\mathrm{Na}^{+}$and $\mathrm{Cl}^{-}$ions with fluoride ions to adsorb onto natural LECA.

\subsection{Regeneration of spent adsorbent}

Regeneration of the spent adsorbent is a key factor which targets the real economy of adsorption system. In addition, the reusable and recoverable aspects can be realized. Therefore, in the present work the spent adsorbent was regenerated to assess its reusability. Fig. 11 shows the regeneration percentage for spent NL, HML and MGML. For spent natural LECA, after 300 min contact time with de-ionized water, only $82 \%$ of used adsorbent could be regenerated. For spent HML and MGML, about 98\% was regenerated after $180 \mathrm{~min}$ and $200 \mathrm{~min}$ respectively. The above first-time regenerated adsorbents underwent a mechanical agitation with $10 \mathrm{mg} / \mathrm{L}$ of fluoride solution and followed by second-time regeneration process with de-ionized water. The results after second regeneration were found to be about 38\%, 63\% and $92 \%$ for NL, HML and MGML respectively for the corresponding contact times. In the same way, the regeneration efficiency was found to be about $11 \%, 27 \%$ and $92 \%$ respectively after fifth cycle. A drastic fall in the regeneration efficiency was observed in NL and HML adsorbents but the efficiency was very much consistent which decreased to about $83 \%$ with a minimum loss of $9 \%$ after second regeneration. Evidently, it can be concluded that $2 \mathrm{M} \mathrm{MgCl}_{2}$ can be used for LECA modification on one hand and for the regeneration process of the spent MGML on the other hand.

\subsection{Adsorption isotherms}

Equilibrium data were fitted onto Langmuir, Freundlich and Temkin isotherm models. Isotherm parameters for natural and modified LECA adsorbents are collected in Table 4, showing an accurate fit of equilibrium data for the three isotherm models, confirmed by the closeness of the regression values, with however a slightly higher correlation coefficient for the Freundlich model. The surface of the adsorbent contained most likely heterogeneous moieties which were uniformly distributed on the surface, accounting for Langmuir, Freundlich and Temkin isotherms [36]. The high value of the adsorption heat $\left(b_{1}\right)$, as well as the low value of the equilibrium binding constant $\left(k_{\mathrm{t}}\right)$ confirmed the fast sorption of fluoride at initial stage and the weak bonding of fluoride on the natural medium surface if compared to the modified adsorbents.

For increasing initial solute concentration, the value of the separation factor $\left(R_{\mathrm{L}}\right)$ decreased from 0.47 to $0.08,0.92$ to 0.53 and 0.41 to 0.06 for NL, HML and MGML, respectively (not shown). A favorable adsorption was therefore shown $\left(0<R_{\mathrm{L}}<1\right)$, which was also confirmed by the Freundlich constant $(n), 2.55,2.27$ and 1.16 for NL, HML and MGML, respectively. 
Table 4

Adsorption Isotherm parameters for fluoride adsorption onto NL, HML and MGML.

\begin{tabular}{lccc}
\hline \multicolumn{1}{c}{ Langmuir } & $\mathrm{NL}$ & $\mathrm{HML}$ & \\
\hline & & & $\mathrm{MGML}$ \\
\hline$q_{\mathrm{m}}(\mathrm{mg} / \mathrm{g})$ & & & \\
$b(\mathrm{~L} / \mathrm{mg})$ & 0.219 & 17.83 & 23.86 \\
$r^{2}$ & 0.95 & 0.151 & 0.285 \\
\multicolumn{1}{c}{ Freundlich } & & 0.97 & 0.94 \\
\hline & $\mathrm{NL}$ & & \\
\hline$k_{\mathrm{f}}$ & 0.521 & $\mathrm{HML}$ & $\mathrm{MGML}$ \\
$n$ & 2.554 & 0.535 & 0.777 \\
$r^{2}$ & 0.98 & 2.273 & 1.616 \\
& & 0.99 & 0.99 \\
Temkin & & & \\
\hline & $\mathrm{NL}$ & $\mathrm{HML}$ & $\mathrm{MGML}$ \\
\hline$k_{\mathrm{t}}$ & 1.712 & 1.162 & 1.079 \\
$b_{1}$ & 19.82 & 18.04 & 12.88 \\
$r^{2}$ & 0.97 & 0.93 & 0.92 \\
\hline
\end{tabular}

The maximum sorption capacity at the expense of the minimum energy was shown for HML from the $q_{\mathrm{m}}$ and $b$ values, $17.83 \mathrm{mg} / \mathrm{g}$ and $0.151 \mathrm{~L} / \mathrm{mg}$ respectively.

Maximum sorption capacity according to the Langmuir constant $\left(q_{\mathrm{m}}\right)$ was found to be $8.53,17.83$ and $23.86 \mathrm{mg} / \mathrm{g}$ for $\mathrm{NL}$, HML and MGML, respectively. Table 5 listed maximum sorption capacities for adsorbents recently used for fluoride removal. As can be seen, maximum sorption capacity for natural LECA was higher than most of them, except polypyrrole-alumina composite, polyaniline-alumina composite, nano-alumina, hydroxyapatite, $\mathrm{Fe}(\mathrm{OH})_{3}$ and $\mathrm{Fe}$ :Al hydrous oxide. For $\mathrm{H}_{2} \mathrm{O}_{2}$-and $\mathrm{MgCl}_{2}$-modified LECA, only $\mathrm{Fe}(\mathrm{OH})_{3}$ and Fe:Al hydrous oxide showed higher maximum sorption capacity. The potential of natural and modified LECA for fluoride adsorption was therefore confirmed.

Table 5

Maximum sorption capacity of some adsorbents for fluoride adsorption.

\begin{tabular}{lcl}
\hline Adsorbent & $q_{\max }(\mathrm{mg} / \mathrm{g})$ & Reference \\
\hline Ceramic adsorbent & 2.16 & {$[2]$} \\
Natural stilbite zeolite modified with Fe(III) & 2.31 & {$[3]$} \\
Magnesia-loaded fly ash cenospheres & 5.10 & {$[7]$} \\
Saponifiedorange juice residue (Al) & 1.03 & {$[25]$} \\
Saponified orange juice residue (Ti) & 0.93 & {$[25]$} \\
Saponified orange juice residue (Sn) & 1.18 & {$[25]$} \\
Saponified orange juice residue (La) & 1.07 & {$[25]$} \\
Polyaniline/alumina composite & 13.0 & {$[39]$} \\
Polypyrrole/alumina composite & 12.0 & {$[39]$} \\
Bone meal & 4.99 & {$[40]$} \\
Treated bone meal by $\mathrm{H}_{2} \mathrm{O}_{2}$ & 6.85 & {$[40]$} \\
La-incorporated chitosan beads & 4.7 & {$[41]$} \\
Uncalcined meixnerite & 5.8 & {$[42]$} \\
Calcined meixnerite & 10.4 & {$[42]$} \\
Al/Fe dispersed in porous granular ceramics & 1.78 & {$[43]$} \\
Light weight concrete materials & 5.15 & {$[44]$} \\
Modified amberlite resin & 3.21 & {$[45]$} \\
Nano-alumina & 14.0 & {$[46]$} \\
Calcium chloride modified natural zeolite & 2.25 & {$[47]$} \\
Hydroxyapatite & 16.38 & {$[48]$} \\
Al(III) modified calcium hydroxyapatite & 3.57 & {$[48]$} \\
Synthetic siderite & 1.71 & {$[49]$} \\
Fe:Al hydrous oxide & 91.7 & {$[50]$} \\
Fe(OH) & 76.98 & {$[50]$} \\
Natural LECA & 8.525 & Present work \\
$\mathrm{H}_{2} \mathrm{O}_{2}$-Modified LECA & 17.83 & Present work \\
MgCl -Modified LECA $^{2}$ Present work \\
\hline
\end{tabular}

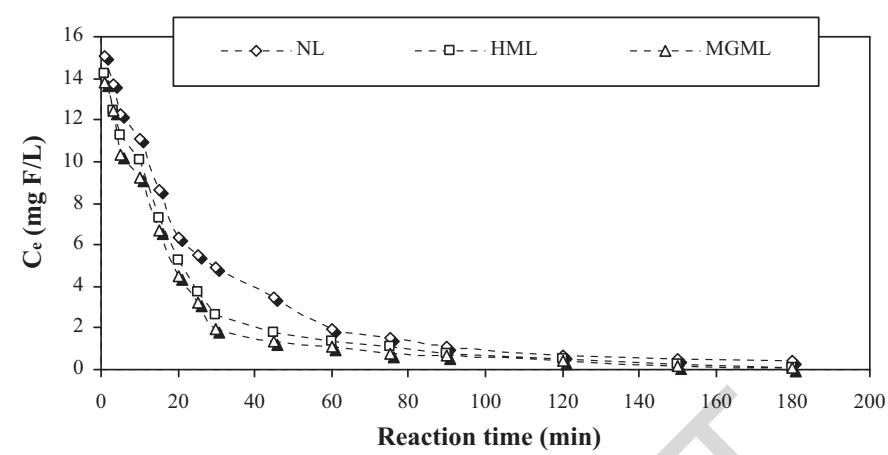

Fig. 12. Time-courses of fluoride concentrations during treatment in the optimal conditions (conditions: pH 5.5; Dose $-6 \mathrm{~g} / \mathrm{L}$; temperature $-20^{\circ} \mathrm{C}$ ).

\subsection{Fluoride removal at optimal condition and effect of competing ions}

The removal of fluoride $(20 \mathrm{mg} / \mathrm{L})$ was investigated in the optimal conditions, namely at $\mathrm{pH} 6,20^{\circ} \mathrm{C}$ and using $10 \mathrm{~g} / \mathrm{L}$ of adsorbent. Experiments were conducted until fluoride concentration reached drinking water standards $(0.75-1.5 \mathrm{mg} / \mathrm{L})$. Fig. 12 shows that after 180 min contact time, fluoride reached concentration values below $0.39,0.1$ and $0.075 \mathrm{mg} / \mathrm{L}$ for NL, HML and MGML, respectively. Standard fluoride levels for drinking water was therefore reached after only $120 \mathrm{~min}(0.69 \mathrm{mg} / \mathrm{L}), 90 \mathrm{~min}$ $(0.73 \mathrm{mg} / \mathrm{L})$ and $75 \mathrm{~min}(0.79 \mathrm{mg} / \mathrm{L})$ contact times for NL, HML and MGML, respectively.

However, various ions co-exist in drinking water which may influence the adsorption of the target ion. In addition and to confirm the efficiency of the considered system, tests on real samples should be implemented. The effect of competing ions such as $\mathrm{SO}_{4}{ }^{2-}, \mathrm{NO}_{3}{ }^{-}, \mathrm{Cl}^{-}, \mathrm{Ca}^{2+}, \mathrm{Na}^{+}$, phosphates, $\mathrm{Mg}^{2+}$ and many other ions have been the purpose of several works in the available literature, and hence the effects of nitrate $(35 \mathrm{mg} / \mathrm{L})$, calcium $(50 \mathrm{mg} / \mathrm{L})$, magnesium ( $50 \mathrm{mg} / \mathrm{L})$, sulfate $(250 \mathrm{mg} / \mathrm{L})$, chloride $(250 \mathrm{mg} / \mathrm{L})$, carbonate $(100 \mathrm{mg} / \mathrm{L})$ and bi-carbonate $(100 \mathrm{mg} / \mathrm{L})$ were examined. The conductivity was adjusted to $1500 \mu \mathrm{ms} / \mathrm{cm}$ using $\mathrm{NaCl}$. In a first step, the sorption capacity was examined at $20 \mathrm{mg} / \mathrm{L}$ initial fluoride concentration with $10 \mathrm{~g} / \mathrm{L}$ adsorbent at $\mathrm{pH}$ 6 in a single system. The reaction time was conducted until the fluoride concentration reached a value below $1.5 \mathrm{mg} / \mathrm{L}$.

In a single system (containing only fluoride and one of the mentioned ions) and in the optimal conditions, the desirable fluoride concentration ( $1.5 \mathrm{mg} / \mathrm{L})$ was observed in the ranges 180 $310 \mathrm{~min}, 95-420 \mathrm{~min}$ and $100-230 \mathrm{~min}$ with NL, HML and MGML respectively. It should however be noted that in the presence of chloride the required fluoride concentration was not achieved, even after 550 min contact time with NL. The whole results can be summarized as follows:

$$
\begin{aligned}
& \mathrm{NL}: \mathrm{Cl}^{-}>\mathrm{NO}_{3}^{-}>\mathrm{SO}_{4}^{2-}>\mathrm{Mg}^{+2}>\mathrm{Ca}^{+2} \\
& \mathrm{HML}: \mathrm{Cl}^{-}>\mathrm{SO}_{4}^{2-}>\mathrm{NO}_{3}^{-}=\mathrm{Mg}^{+2}>\mathrm{Ca}^{+2} \\
& \mathrm{MGML}: \mathrm{SO}_{4}^{2-}>\mathrm{Cl}^{-}>\mathrm{Mg}^{+2}>\mathrm{NO}_{3}^{-}=\mathrm{Ca}^{+2}
\end{aligned}
$$

In a second step, fluoride removal was examined in binary systems. The results show that after $600 \mathrm{~min}$ contact time fluoride concentration decreased from 20 to $5.43 \mathrm{mg} / \mathrm{L}$ for NL, while the required concentration $(1.5 \mathrm{mg} / \mathrm{L})$ was reached after 575 and 315 min in the case of HML and MGML respectively, showing the efficiency of the modified LECA.

Therefore, the required fluoride concentration can be achieved in the presence of competing ions, but at the expense of a higher 
contact time. It can also be observed that in the presence of $\mathrm{SO}_{4}{ }^{2-}$, $\mathrm{NO}_{3}{ }^{-}$and $\mathrm{Cl}^{-}$, the required time is higher than those observed for $\mathrm{Mg}^{+2}$ and $\mathrm{Ca}^{+2}$. The negligible effect of $\mathrm{Ca}^{+2}$ on the fluoride adsorption on modified and non-modified LECA can be attributed to increasing positive charge on the oxide surfaces and/or forming a positively charged surface or formation of calcium fluoride $[25,37]$. The higher interference effect was observed for $\mathrm{Cl}^{-}$and $\mathrm{SO}_{4}{ }^{2-}$, Which may be due to formation of inner and outer sphere complexes, whereas it was lower in the case of chloride which can form only outer sphere complexes [38].

Some disagreement can be found in the literature regarding the effect of competing ions. In the removal of fluoride using orange waste loaded with multi-valent metal ions, it was reported that the influence of coexisting $\mathrm{NO}_{3}{ }^{-}$and $\mathrm{Cl}^{-}$ions for fluoride removal from binary mixture appeared negligible. But, the presence of $\mathrm{Ca}^{2+}$ ions in the fluoride solution enhanced the uptake capacity, whereas in the presence of $\mathrm{SO}_{4}{ }^{2-}$ lower fluoride adsorption was observed [25]. In the removal of fluoride by acid activated water treatment sludge, $\mathrm{NO}_{3}{ }^{-}, \mathrm{CO}_{3}{ }^{2-}$ and $\mathrm{SO}_{4}{ }^{2-}$ were found to had an adverse effect on fluoride adsorption capacity, while sorption capacity increased in the presence of $\mathrm{Fe}^{+2}, \mathrm{Na}^{+}$and $\mathrm{Ca}^{+2}$ [5]. The slight increase in fluoride removal previously reported in the presence of chloride and nitrate ions [2] was not in agreement with the present work, contrarily to the slight decrease observed in the presence of sulfate [2]. In the removal of fluoride by Al-Ce hybrid adsorbent, the impact of some ionic species was found to be in the following order: $\mathrm{HPO}_{4}{ }^{2-}>\mathrm{SO}_{4}{ }^{2-}>\mathrm{SiO}_{3}{ }^{2-}>\mathrm{HCO}_{3}{ }^{-}>\mathrm{Cl}^{-}$[4]; the negligible chloride effect was not in agreement with our findings, contrarily to the high sulfate effect.

To summarize the effect of competing ions, it was found that positively charged ions have positive or negligible effect on fluoride adsorption, while negatively charged ions had an adverse effect on fluoride adsorption. The increase of fluoride adsorption in the presence of positively charged ions may be due to increasing net positive charge on the adsorbent or the formation of complex with fluoride ions, while negatively charged ions may compete with fluoride ions to adsorb on the adsorbent.

\section{Summary}

Modification of natural LECA with $\mathrm{H}_{2} \mathrm{O}_{2}$ and $\mathrm{MgCl}_{2}$ improved the specific surface area, as well as adsorption capacity. The results show that fluoride removal increased with increasing initial fluoride concentration, adsorbent mass and reaction time and decreased with increasing $\mathrm{pH}$ and ionic strength. With respect to the other parameters, $\mathrm{pH}$ showed the most significant impact; it influences the positive charge on the adsorbent and hence improved adsorption capacity. Equilibrium data were accurately fitted onto Freundlich, Langmuir and Temkin isotherm models, with the highest correlation coefficient found for the Freundlich isotherm model. Maximum sorption capacity was 8.53, 17.83 and $23.86 \mathrm{mg} / \mathrm{g}$ for NL, HML and MGML, respectively. Among pseudofirst order, pseudo-second order and modified pseudo-first order, pseudo second order model was found to give the best kinetic fitting. The considered adsorbents had only a limited impact on conductivity and turbidity of fluoride solutions. After five cycle adsorption and/or regeneration, about 11,27 and $83.4 \%$ of spent NL, HML and MGML were regenerated, showing the efficiency of $\mathrm{Mg}^{2+}$ modification. Negatively charged ions had a competing effect on fluoride adsorption.

\section{References}

[1] Shubo D, Han L, Wei Z, Jun H, Gang Y. Mn-Ce oxide as a high-capacity adsorbent for fluoride removal from water. J Hazard Mater 2011:186:1360-6.
[2] Nan C, Zhenya Z, Chuanping F, Miao L, Dirui Z, Rongzhi C, et al. An excellent fluoride sorption behavior of ceramic adsorbent. I Hazard Mater 2010;183:460-5

[3] Youbao S, Qinghua F, Junping D, Xiaowei C, Jiaqiang X. Removal of fluoride from drinking water by natural stilbite zeolite modified with Fe (III). Desalination 2011;277:121-7.

[4] Han L, Shubo D, Zhijian L, Gang Y, Jun H. Preparation of Al-Ce hybrid adsorbent and its application for defluoridation of drinking water. J Hazard Mater 2010;179:424-30.

[5] Soydoa V, Sriwilai K, Siriluk C. Removal of fluoride in aqueous solution by adsorption on acid activated watertreatment sludge. Appl Surf Sci 2010;256:5458-62.

[6] Amit B, Eva K, Mika S. Fluoride removal from water by adsorption-a review. Chem Eng J 2011;171:811-40.

[7] Xiaotian X, Qin L, Hao C, Jianfeng P, Li S, Hao A, et al. Adsorption of fluoride from aqueous solution on magnesia-loaded fly ash cenospheres. Desalination 2011;272:233-9.

[8] Vikas K, Neetu T, Dinesh D, Nalini S, Ashutosh S, Nishith V. Development of bimetal doped micro- and nano multi-functional polymeric adsorbents for the removal of fluoride and arsenic(V) from wastewater. Desalination 2011. 282:27-38.

[9] Ebrahim MK, Kaan Y, Nihan U, Mansur Z, Reham MAS. Modeling of adsorption of toxic chromium on natural and surface modified lightweight expanded clay aggregate (LECA). Appl Surf Sci 2013;287:428-42.

[10] American Water Work Association. In: Standard methods for the examination of water and wastewater. 21st ed. Washington, DC, USA; 2005

[11] Azizian S. Kinetic models of sorption: a theoretical study. J Colloid Interface Sci 2004;276:47-52

[12] Yang X, Al-Duri B. Kinetic modeling of liquid-phase adsorption of reactive dyes on activated carbon. J Colloid Interface Sci 2005;287:25-34.

[13] Saeid A, Hadis B. Adsorption kinetics at solid/solution interface: statistical rate theory at initial times of adsorption and close to equilibrium. Langmuir 2008;24:11669-75.

[14] Marian AN, Alfred AC, Tanja B, George WF. The use of lightweight expanded clay aggregate (LECA) as sorbent for PAHs removal from water. J Hazard Mater 2012;217:360-5

[15] Ana VD, José T, Idália R, Carvalho AJP, Candeias AJE. Selection of a support matrix for the removal of some phenoxyacetic compounds in constructed wetlands systems. Sci Total Environ 2007;380:237-46.

[16] Anthony JW, Bideaux RA, Bladh KW, Nichols MC.In: Handbook of mineralogy. Chantilly: Mineralogical Society of America; 2001.

[17] Brezinski DR.In: An infrared spectroscopy atlas for the coatings industry. Pennsylvania: Federation of Societies for Coating Technology; 1991.

[18] Carriazo JG, Centeno MA, Odriozola JA, Moreno S, Molina R. Effect of Fe and Ce on Al-pillared bentonite and their performancein catalytic oxidation reactions. Appl Catal A 2007;317:120-8.

[19] Nicoletta M, Marta PB, Chiara R, Alessandro P. The effects of atmospheric multipollutants on modern concrete. Atmos Environ 2003;37:4701-12.

[20] Hari P, Bimala P, Kedar NG, Katsutoshi I, Keisuke O, Hidetaka K, et al. Adsorption behavior of orange waste gel for some rare earth ions and itsapplication to the removal of fluoride from water. Chem Eng J 2012;195-196:289-96.

[21] Xiaomin D, Dinesh M, Charles UPJ, Shuo Y. Remediating fluoride from water using hydrous zirconium oxide. Chem Eng J 2012;198-199:236-45.

[22] Yulin T, Xiaohong G, Jianmin W, Naiyun G, Martin RM, Charles CC. Fluoride adsorption onto granular ferric hydroxide: effects of ionic strength, $\mathrm{pH}$, surface loading and major co-existing anions. J Hazard Mater 2009;171:774-9.

[23] Saeid A, Bahare Y. Adsorption of 18-crown-6 from aqueous solutionon granular activated carbon: a kinetic modeling study. J Colloid Interface Sci 2006;299:112-5

[24] Sujana MG, Anand S. Iron and aluminum based mixed hydroxides: a novel sorbent for fluoride removal from aqueous solutions. Appl Surf Sci 2010:256:6956-62.

[25] Hari P, Bimala P, Katsutoshi I, Hidetaka K, Keisuke O, Hiroyuki H, et al. Adsorptive removal of fluoride from aqueous solution usingorange waste loaded with multi-valent metal ions. J Hazard Mater 2011;192:676-82.

[26] Teng SX, Wang SG, Gong WX, Liu XW, Gao BY. Removal of fluoride by hydrous manganese oxide-coated alumina: performance and mechanism. J Hazard Mater 2009;168:1004-11.

[27] Xin-Hua W, Rui-Hong S, Hui-Chun Y, Yi-Jing S, Guang-Bin D, Sen Y, et al. Fluoride adsorption on carboxylated aerobic granules containing Ce(III). Bioresour Technol 2013;127:106-11.

[28] Yuming Z, Chunxiang Y, Yun S. Adsorption of fluoride from aqueous solution on $\mathrm{La}^{3+}$-impregnated cross-linked gelatin. Sep Purif Technol 2004;36:89-94.

[29] Yaping Z, Xiuyan L, Lu L, Fuhua C. Fluoride removal by Fe(III)-loaded ligand exchange cotton cellulose adsorbent from drinking water. Carbohydr Polym 2008;72:144-50

[30] Shihabudheen MM, Atul KS, Ligy P. Manganese-oxide-coated alumina: a promising sorbent for defluoridation of water. Water Res 2006;40:3497-506.

[31] Ersoy B, Sariisik A. Dikmen S, Sariisik G. Characterization of acidic pumice and determination of its electrokinetic properties in water. Powder Technol 2010;197:129-35

[32] Wang Y, Reardon EJ. Activation and regeneration of a soil sorbent for defluoridation of drinking water. Appl Geochem 2001:16:531-9.

[33] Mohammad NS, Sivasankar V, Mansur Z, Senthilkumar M. Surface modification of pumice enhancing its Fluoride uptake capacity: an Insight into kinetic and thermodynamic studies. Chem Eng J 2013;228:192-204. 
[34] Miltiadis Z, Areti G, Panagiota S, Yiannis D, Ierotheos Z. Removal of phosphate from natural waters using innovative modified bentonites. Appl Clay Sci 2012;62-63:101-6.

[35] Ting L, Kun W, Lihua Z. Removal of phosphorus by a composite metal oxide adsorbent derived from manganese ore tailings. J Hazard Mater 2012;217218:29-35.

[36] Low L, Teng T, Ahmad A, Morad N, Wong Y. A novel pretreatment method of lignocellulosic material as adsorbent and kinetic study of dye waste adsorption. Water Air Soil Pollut 2011;218:293-306.

[37] Kamble SP, Dixit P, Rayalu SS, Labhsetwar NK. Defluoridation of drinking water using chemically modified bentonite clay. Desalination 2009;249:687-93.

[38] Sivasankar V, Ramachandramoorthy T, Andre D. Manganese dioxide improves the efficiency of earthenware in fluoride removal from drinking water. Desalination 2011;272:179-86.

[39] Karthikeyan M, Satheesh Kumar KK, Elango KP. Conducting polymer/alumina composites as viable adsorbents for the removal offluoride ions from aqueous solution. J Fluorine Chem 2009;130:894-901.

[40] Shan G, Jing C, Zhenggui W. Study on the fluoride adsorption of various apatite materials in aqueous solution. J Fluorine Chem 2009;130:1035-41.

[41] Dilip T, Sneha J, Amit B, Nitin L, Sadhana R. Synthesis of La-incorporated chitosan beads for fluoride removal from water. J Fluorine Chem 2010; 131:373-7.
[42] Qinghai G, Eric JR. Fluoride removal from water by meixnerite and its calcination product. App Clay Sci 2012;56:7-15

[43] Nan C, Zhenya Z, Chuanping F, Dirui Z, Yingnan Y, Norio S. Preparation, characterization of porous granular ceramic containing dispersed aluminum and iron oxides as adsorbents for fluoride removal from aqueous solution. J Hazard Mater 2011;186:863-8.

[44] Ensar O. Equilibrium isotherms and kinetics studies for the sorption of fluoride on light weight concrete materials. Colloids Surf A 2007;295:258-63.

[45] Imam Bakhsh S, Shahabuddin M, Bhanger MI. An excellent fluoride sorption behavior of modified amberlite resin. J Hazard Mater 2010;176:186-92.

[46] Eva K, Amit B, Umesh K, Mika S. Defluoridation from aqueous solutions by nano-alumina: characterization andsorption studies. J Hazard Mater 2011;186:1042-9.

[47] Zhijie Z, Yue T, Mingfeng Z. Defluorination of wastewater by calcium chloride modified natural zeolite. Desalination 2011;276:246-52.

[48] Yulun N, Chun H, Chuipeng K. Enhanced fluoride adsorption using Al (III) modified calcium hydroxyl apatite. J Hazard Mater 2012;233-234:194-9.

[49] Qiong L, Huaming G, Yue S. Adsorption of fluoride on synthetic siderite from aqueous solution. J Fluorine Chem 2010;131:635-41.

[50] Sujana MG, Soma G, Vasumathi N, Anand S. Studies on fluoride adsorption capacities of amorphous Fe/Al mixed hydroxidesfrom aqueous solutions. J Fluorine Chem 2009;130:749-54. 